\title{
La toponimia como recurso didáctico para la enseñanza de la Geografía. Una propuesta a partir de tres salidas de campo en la Huerta de València (España)
}

\section{Toponymy as a Didactic Resource for Teaching Geography: A Proposal Based on Three Field Trips to Huerta de Valencia (Spain)}

\author{
Álvaro Francisco Morote Seguido* \\ Universitat de València \\ https:/ / orcid.org/0000-0003-2438-4961 \\ alvaro.morote@uv.es \\ Joan Carles Membrado Tena \\ Universitat de València \\ http:/ / orcid.org/0000-0001-6961-1449 \\ joan.membrado@uv.es
}

Recibido: 01/12/2020; Revisado: 03/04/2021; Aceptado: 10/05/2021

\begin{abstract}
Resumen
El objetivo de este trabajo es presentar una propuesta didáctica para el profesorado de Educación Primaria sobre el uso de la toponimia a partir de 3 salidas de campo en la Huerta de València (España). Ante la falta de trabajos sobre educación, toponimia y geografía en el área de estudio, este trabajo aportará significativamente al conocimiento sobre la didáctica de la geografía con el uso de salidas de campo en relación con la toponimia, pero también servirá de paradigma para la comunidad docente, ya que podrá aplicarlo a su territorio de referencia.
\end{abstract}

Palabras clave: Toponimia, propuesta didáctica, salida de campo, geografía, Huerta de València.

\section{Abstract}

This research makes a didactic proposal to Primary School teachers regarding the use of toponymy, based upon three field trips to Huerta de Valencia (Spain). Given the scarcity of scholarly work at the

*Autor de correspondencia / Corresponding author. 
nexus of pedagogy, toponymy and geography, this study significantly contributes to the teaching of geography through toponymy based on field trips, but it also serves as a paradigm for the wider teaching community, as it may be applied to other areas.

Keywords: Toponymy, Didactic Proposal, Field Trips, Geography, Huerta de Valencia.

\section{INTRODUCCIÓN ${ }^{1}$}

La toponimia hace referencia a los nombres de lugar y describe las características humanas y físicas del territorio (sustrato geológico, vegetación, topografía, sistemas de ocupación, fauna, etc.) (Gómez et al., 2015). El estudio de la toponimia se basa principalmente en tres disciplinas humanas (o sociales) claramente definidas como son la historia, geografía y la lingüística (DoRION, 1984). De esta forma se generan especialidades mixtas, como la geografía histórica, la historia de la lengua y las peculiaridades léxicas del lenguaje geográfico (ARROYO, 2018). De carácter plural e interdisciplinario (ORDINAS, 2014), la toponimia es, por tanto, un recurso plausible en el análisis territorial (FERNÁNDEZ et al., 2019) que, sin embargo, había sido poco tratada desde la geografía hasta finales del s. xx. Al respecto, DARBY (1957) ya advirtió de la limitación que suponía no tener en cuenta la vertiente geográfica de esta disciplina y dejar únicamente su estudio a la filología. Por su parte WEST (1954) ya indicaba que la clasificación y distribución de los topónimos pertenecía al campo de la geografía, mientras que el estudio de su etimología correspondía al mundo de la filología. Teniendo en cuenta estas cuestiones, esta investigación cobra un notable interés debido a varios motivos. El primero de ellos es la utilidad de la toponimia como recurso didáctico para la enseñanza de la geografía. Esto se hace más evidente en la etapa de Educación Primaria (objeto de estudio) debido a la escasa formación geográfica y percepción de limitada utilidad de esta ciencia, incluso por parte de los/as futuros/as maestros/as (PARRA y Morote, 2020). El segundo de ellos es el área de estudio donde se inserta esta propuesta (la Huerta de València, España), un espacio socio-cultural y ambiental que ofrece multitud de posibilidades para enseñar a interpretar el territorio y lograr un aprendizaje significativo. Y, en tercer lugar, la escasez de estudios sobre toponimia y didáctica de la geografía realizados en el área de estudio. Por tanto, este trabajo aportará una contribución a la temática de didáctica de la geografía en relación con la toponimia, pero también será un ejemplo para la comunidad docente, ya que puede ser fácilmente tomado como referencia a su territorio.

Respecto a la enseñanza de la geografía, ORDINAS y Binimelis (2018) destacan la importancia del binomio toponimia-geografía. Esto también ha sido indicado por diferentes autores que han demostrado que esta disciplina resulta de enorme interés para entender e interpretar el entorno (LUISA DE TORT, 2004). Sin embargo,

1 Esta investigación se inserta en el proyecto «Las representaciones sociales de los contenidos escolares en el desarrollo de las competencias docentes (PGC2018-094491-B-C32)» financiado por el Ministerio de Ciencia, Innovación y Universidades y cofinanciado con fondos FEDER de la UE. 
uno de los problemas con los que se ha enfrentado esta disciplina ha sido su utilización en la enseñanza asociada a un aprendizaje exclusivamente memorístico (ORDINAS y BINIMELIS, 2018). Diferentes autores han puesto de manifiesto que este aprendizaje y estudio, asociado a la geografía regional, ha conllevado al abuso de la memorización y de ejercicios de repetición y reproducción de topónimos (Ballantyne, 1996; Morote, 2020). Según Comes y Dantí (2003) tener en cuenta la toponimia que se asocia a la experiencia o al contexto vital de los discentes, y la propuesta de actividades orientadas a analizar su sentido o significado, puede estimular el interés por estudiar esta ciencia. Por ello, y como afirman Gómez et al. (2015), la oportunidad de fomentar el análisis aplicado de la toponimia en los programas educativos debe apoyarse en la relevancia del saber cotidiano, donde se inserta también el conocimiento de los topónimos, para la comprensión de la sociedad actual y pasada y del medio en el que se asienta (EsTePA et al., 2011).

Algunas de las propuestas que se pueden implementar en didáctica de la geografía en relación con la toponimia deberían vincularse con la enseñanza activa, por ejemplo, con metodologías de aprendizaje por descubrimiento a través de procedimientos (Gómez-RUIZ, 2010; MARRón, 2011), la obtención de toponimia a partir de nuevas Tecnologías de la Información Geográfica (TIG) como Iberpix (Crespo, 2019; Sebastián y De Miguel, 2017), o la importancia del aprendizaje fuera del aula (De LÁZARO et al., 2014; MARRón, 2013). En esta última línea, cobran un notable protagonismo y utilidad de la toponimia las salidas de campo, uno de los recursos clásicos de la geografía. En este sentido, en un trabajo reciente llevado a cabo por Morote (2019) se ha realizado un análisis de la evolución en las últimas décadas de las temáticas y autores sobre las salidas de campo en geografía. Este autor ha demostrado como en los últimos años han cobrado protagonismo los trabajos vinculados con las TIC y con los estudios de caso. Por ejemplo, de estos últimos, donde se insertaría la propuesta aquí presentada, destacan las contribuciones de Crespo (2012), Delgado et al., (2013), Gómez et al. (2017), Fernández (2017) o López-Fernández y Peral (2017).

En relación con los trabajos vinculados con la toponimia, la mayoría de los estudios se han centrado en aspectos semánticos, filológicos, etimológicos e históricos, pero también geográficos. En España, entre estos últimos cabe mencionar los realizados por MEMBRAdo $(2017 ; 2018)$ o GARCíA DE Celis et al. (2018). En el panorama internacional son reseñables trabajos toponímicos desde la geografía como los de Seidl (2018), AldERMAn (2016), Siwei et al. (2016) o CoNEDERA et al. (2017).

En España, respecto a los trabajos sobre didáctica de la geografía y toponimia, de los años noventa destacan publicaciones sobre propuestas didácticas (MAs, 1999; TORRES, 1995), y sobre problemas, métodos y enseñanza de la toponimia (FrAGo, 1991). En el s. XXI han sido publicadas diferentes investigaciones sobre la utilidad de la toponimia para la enseñanza de la geografía, como la de ORDINAS (2014) acerca del redescubrimiento para el colectivo docente de su utilidad y de su enseñanza mediante técnicas y aplicaciones renovadas. Otras se vinculan con las aportaciones que puede tener esta disciplina para la didáctica y la propuesta de recursos del entorno (espacios vulnerables) (GómEz et al., 2015). También 
destacan investigaciones que tratan sobre experiencias para la enseñanza del paisaje natural como la de ORDINAS y BinIMELIS (2018). Estos últimos definen la valiosa información obtenida de los nombres de lugar sobre múltiples aspectos del territorio como «función pedagógica de la toponimia», que constituye una importante contribución a la consolidación de la conciencia territorial, base esencial de la cohesión y la coherencia social (OrdinAs y Binimelis, 2018: 389). Por su parte, ORDINAS (2014) añade que la enseñanza basada en la toponimia permite la consecución de objetivos como la identificación del entorno físico y humano, a partir de su denominación, y el impacto de las actividades antrópicas sobre el medio, al igual que las transformaciones producidas a lo largo del tiempo, que deben ser cualidades que conviene que sean conocidas por las nuevas generaciones. De ahí, como expresan ORDINAS y BINIMELIs (2018) el interés por mostrar la utilidad de esta disciplina en las clases de geografía y/o ciencias sociales.

Un trabajo reciente sobre la utilidad de la toponimia es el de Domínguez et al. (2020) donde se evalúa y analiza la realización de una práctica de aula sobre el análisis de la toponimia del callejero con perspectiva de género en las diferentes asignaturas del área. Por tanto, el objetivo principal de este trabajo es conocer la utilidad de la toponimia, su aplicación, así como su efectividad en cuanto a introducción de la perspectiva de género. Otros trabajos en el contexto español ponen de manifiesto la importancia que adquiere la toponimia como fuente de conocimiento para la interpretación del territorio como los de RIESCO (2010) o LUISA DE TORT (2014). En el ámbito internacional, destacan referencias sobre toponimia y revalorización del paisaje (ALDERMAn y Reuben, 2020; MEMBRAdo e IRANZO, 2017; 2018), y sobre toponimia, pedagogía e interpretación del paisaje (HeIKKILA, 2008; AldERMAN, 2016). También, cabe indicar algunas contribuciones llevadas a cabo en el ámbito latinoamericano como las relacionadas con la propuesta de recursos didácticos (cartografía) en Argentina (GILIO, 2015), o la utilidad didáctica que tiene la toponimia para enseñar geografía como pone de manifiesto VALENZUELA (2010) en México.

El objetivo de este trabajo es presentar una propuesta didáctica para el profesorado de Educación Primaria sobre el uso de la toponimia a partir de 3 salidas de campo en la Huerta de València (España). Por tanto, lo que se pretende es, por un lado, mostrar ejemplos de cómo interpretar («leer») el territorio a partir de la toponimia a modo de estudio de caso y, por otro, ofrecer a la comunidad docente un ejemplo de cómo utilizar la toponimia para la enseñanza y que fácilmente se puede adaptar a otras áreas de estudio.

\section{2. ÁREA DE ESTUDIO}

El área de estudio es la Huerta de València (España), un paisaje cultural testimonio de la actividad agrícola de sus moradores a lo largo de los últimos dos mil años y un paradigma de las llanuras mediterráneas con un rico paisaje agrario basado en el aprovechamiento hidráulico (IRANZO, 2014). Con $621 \mathrm{~km}^{2}$ y más de 
1,5 millones de habitantes (cerca 2.500 hab./ $\mathrm{km}^{2}$ ), la Huerta de València (Horta de València, en valenciano) es también el nombre de la comarca más poblada de la Comunitat Valenciana, en la que se encuentra su capital y principal ciudad (València) pero, también varias poblaciones que superan los 50.000 habitantes (Torrent, Paterna) y 30.000 habitantes (Mislata, Burjassot, Manises) (Figura 1). Un rasgo característico de esta área es la pérdida de espacio agrario debido a la expansión de los usos urbanos. El crecimiento urbanístico descontrolado de València y su entorno a partir de 1960 provocó su progresiva reducción y degradación. Hubo dos momentos especialmente críticos de sellado de los suelos agrícolas: 1) durante el desarrollismo franquista (1960 a 1975), momento de crecimiento continuo (compacto y en altura), industrialización y construcción del Plan Sur (nuevo cauce del río Turia); y 2) durante la burbuja inmobiliaria española (19972007), en el que predominó el crecimiento urbano discontinuo (urban sprawl) y de las infraestructuras de servicios (comerciales, logísticos portuarios, sanitarios, educativos).

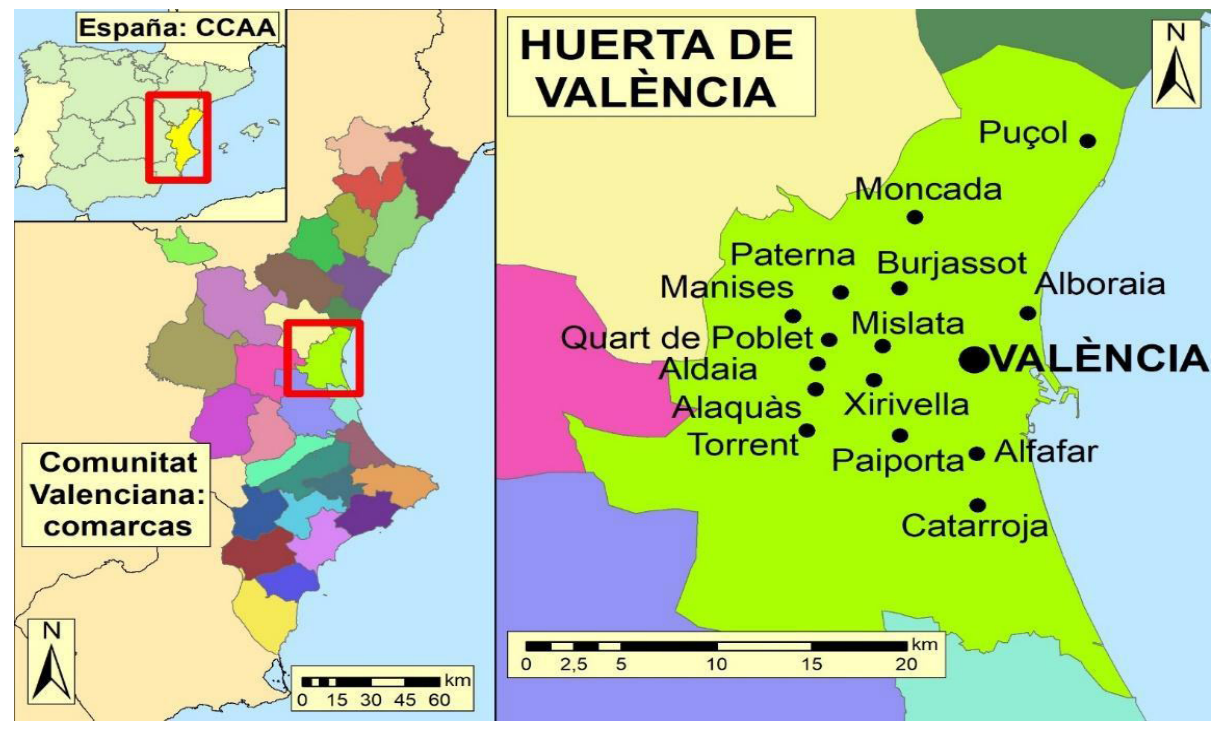

Figura 1. Área de estudio. Comarca de l'Horta o Huerta de València Elaboración propia con datos del ICV (Institut Cartogràfic Valencià).

El crecimiento urbano durante el último medio siglo a lo largo de las principales vías de acceso a la ciudad de València provocó la desconexión entre sí de su huerta tradicional, y creó bolsas de cultivos hortícolas aisladas donde la estructura y funcionamiento del paisaje agrario quedaba notablemente truncada. Entre 1956 y 2015 la huerta pasó de 15.000 a 6.000 ha (una reducción del 60\%) (SORIANO, 2015). Solo durante 1990 y 2009, en plena burbuja inmobiliaria, la huerta 
en la comarca se redujo de 10.000 a menos de 7.000 ha: si el ritmo de destrucción del periodo 1990-2009 se hubiera mantenido estable, este espacio habría desaparecido por completo en solo 63 años (MEMBRADO, 2014).

La crisis económica iniciada en 2008 puso freno al proceso regresivo hortícola y, a pesar de las medidas de protección tomadas por el Consell de la Generalitat Valenciana para su protección institucional (aprobación del Plan de Acción Territorial de la Huerta en 2018), el futuro de lo que queda de la Huerta de València es incierto, ya que el relevo generacional entre los agricultores no está garantizado dada la escasa rentabilidad de los cultivos y el alto valor inmobiliario del suelo («barbecho social»), por su proximidad a la ciudad de València.

Uno de los elementos patrimoniales mejor preservados de este deteriorado espacio es su toponimia, debido al carácter arcaizante propio del lenguaje de los nombres de lugar. En este trabajo se muestra un ejemplo didáctico de análisis toponímico del paisaje, centrado en el espacio hortícola entre la Universitat de València (Campus dels Tarongers), la Universitat Politècnica de València (Campus de Vera), el límite nordeste del término de València y el sur del de Alboraia. Se trata de un espacio donde una parte de la huerta sobrevive de manera más o menos precaria y otra que desapareció hace ya décadas y puede ser reconstituida virtualmente gracias a los nombres de lugar que aún persisten. Desde el punto de vista didáctico, el análisis de la toponimia huertana, sobre un entorno que hoy en día está en gran parte sellado, confirma el predominio histórico de este paisaje agrícola. Este paisaje, gran parte del cual sobrevive solo gracias a sus topónimos, forma parte de la identidad comarcal y, como rasgo identitario, es prioritaria su revalorización, tras décadas de destrucción, degradación y abandono.

\section{MATERIAL Y MÉTODOS}

La propuesta didáctica que aquí se expone, se realiza en el Grado en Maestro/a en Educación Primaria (Facultad de Magisterio, Universitat de València, España), concretamente en la asignatura de «Didáctica de las Ciencias Sociales. Aspectos aplicados» (código 33651). Esta asignatura, obligatoria y de carácter teórico-práctico ( 4,5 créditos) se imparte en el $4^{\circ}$ curso. En relación con el Plan de Estudios del Grado en Maestro/a en Educación Primaria cabe indicar que, junto a la asignatura de «Didáctica de las Ciencias Sociales. Aspectos básicos» $\left(3^{\circ}\right.$ curso) son las únicas materias de carácter obligatorio en las que se insertan contenidos geográficos. La asignatura de $3^{\circ}$ tiene el objetivo de enseñar qué contenidos sobre ciencias sociales se pueden tratar en la Educación Primaria, mientras que la de $4^{\circ}$, donde se realiza esta propuesta, tiene la finalidad de cómo enseñar ciencias sociales. Por tanto, esta propuesta sirve para mostrar cómo se pueden enseñar estas ciencias, y más concretamente en relación con contenidos geográficos a partir de la toponimia que se puede explicar con la realización de salidas de campo y teniendo como marco geográfico (en parte desaparecido) de la Huerta de València.

En cuanto al currículo vigente de Ciencias Sociales, si se tiene en cuenta 
el Decreto del Consell de la Generalitat Valenciana (108/2014 de 4 de julio), los contenidos que se explican durante las salidas de campo se enmarcan principalmente en el Bloque 2 «El mundo en que vivimos: estudio del espacio geográfico, desde lugares próximos hasta regiones que tienen una dimensión global». En este bloque se estudia la distribución y localización de los elementos que configuran el medio físico y su interacción con la acción humana que da lugar a una diversidad de paisajes. Dicha interacción se plantea también desde desafíos que han de superar las sociedades como es el logro del desarrollo sostenible y que requieren un conocimiento de los elementos y sus conexiones que configuran el espacio geográfico en una variedad de escala. En este bloque se concretan aspectos procedimentales apuntados en el bloque anterior.

Además, cabe insistir que, durante las salidas de campo, la toponimia es un recurso complementario que ayuda a entender determinados contenidos dentro de las ciencias sociales. En este sentido, dentro del contexto de la asignatura, el objetivo de las salidas es enseñar al futuro profesorado de Educación Primaria la potencialidad que ofrece el entorno más próximo para explicar aspectos histórico-geográficos. Especialmente, se priorizan determinados elementos que puedan dar lugar al debate y reflexión sobre los problemas sociales y ambientales relevantes en relación con la economía, demografía, urbanización, agricultura, paisaje, patrimonio, historia, toponimia, riesgos naturales y cambio climático (entre otros). La toponimia no es, por tanto, el objetivo principal de las salidas de campo que se desarrollan en la asignatura (pero sí del actual trabajo), sino que se trata de un recurso complementario para llevar a cabo una mejor interpretación, lectura y explicación del territorio. Por ello, en relación con la enseñanza, uno de los objetivos del profesorado que implementa estas salidas de campo es que los discentes valoren la toponimia como un recurso didáctico y que sepan explicar sus potencialidades sobre cualquier área de estudio cuando tengan que llevar a cabo su labor docente. En este sentido, aunque no es objetivo de analizar en esta contribución, el resultado de la realización de estos itinerarios es notablemente positivo, tanto por las opiniones mostradas por el alumnado, como por las propuestas de salidas de campo que realizan en una de las prácticas entregables de la asignatura.

En cuanto a los materiales para las salidas de campo se facilitan al alumnado 3 dossiers donde quedan reflejados los itinerarios. Dentro de estos se incluyen diferentes mapas y fotografías aéreas donde se puede observar una evolución cronológica del área de estudio y los topónimos que se explican. En primer lugar, se incorpora la cartografía catastral de los Bosquejos Planimétricos mandados formar por la Ley de 24 de agosto de 1896 que, para el caso de la ciudad de València, finalizaron en 1902. Estos mapas destacan porque fue la primera cartografía catastral que cubrió todo el territorio nacional (1:25.000), siendo el precedente del actual Mapa Topográfico Nacional (MTN). Esta cartografía es interesante, además, por el gran número y variedad de topónimos, especialmente los que se refieren a infraestructuras (vías de comunicación), viviendas y actividades económicas. En segundo lugar, se añade una captura de imagen de la fotografía aérea del Ejército del Aire (1956), también conocida como la del Vuelo Americano. Le sigue 
la fotografía aérea de 1978 y una actual procedente del visor del Institut Cartogràfic Valencià (ICV). Finalmente, el dossier concluye con un mapa topográfico del área de estudio donde se recogen los topónimos actuales (ICV). Además, para el caso de la segunda salida de campo se añade una cartografía de zonas inundables del Plan de Acción Territorial sobre prevención de Riesgos de Inundaciones de la Comunidad Valenciana (PATRICOVA) (accesible también desde el ICV).

\section{PROPUESTA Y DESCRIPCIÓN DE LAS SALIDAS DE CAMPO}

\subsection{Salida de campo 1. Configuración y evolución histórica de la Huerta de València}

La primera salida de campo tiene el objetivo de dar a conocer al alumnado los diferentes elementos geográficos que se pueden explicar sobre la Huerta de València en relación con la vegetación, actividades económicas, usos urbanos y patrimonio hidráulico (Figura 2). En la primera parte del itinerario se presta especial atención al proceso histórico de la configuración de este espacio agrícola y de los principales problemas a los que se enfrenta: la urbanización, la contaminación de las aguas de riego (Figura 3), el problema del relevo generacional de los agricultores y la rentabilidad de los cultivos.

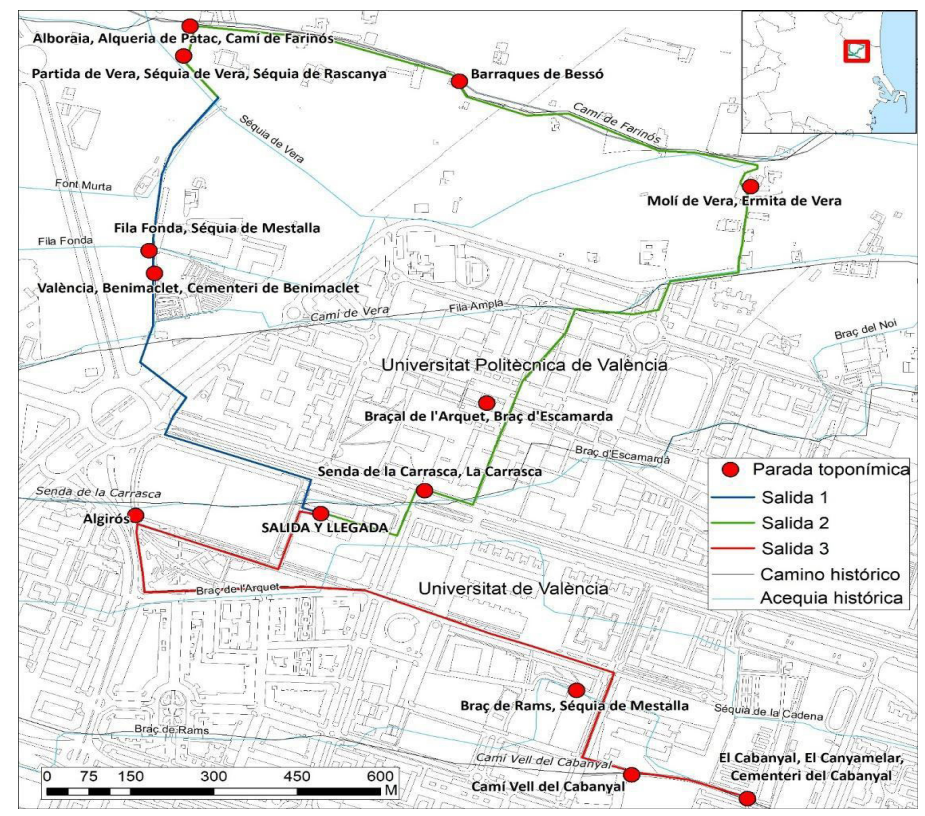

Figura 2. Itinerario de las 3 salidas de campo. Elaboración propia con datos del Institut Cartogràfic Valencià (ICV). ${ }^{2}$

2 En este mapa se han recogido todos los topónimos que se explican. Como «parada toponímica» se 
En cuanto la toponimia, durante este primer recorrido, los nombres de lugar se utilizan para explicar la configuración y transformación histórica y del sistema de regadío de la Huerta de València. Respecto a la primera cuestión, se explica el origen y significado de València que, hace referencia a una colonia romana fundada en el 138 a. C. Su explicación durante el itinerario sirve para comprender el proceso histórico de la configuración de esta ciudad y del territorio de la Huerta ya desde época romana. Se trataba de un espacio fértil que, a lo largo de más de dos milenios, ha sido transformado por la actividad humana tras el paso de diferentes culturas y sociedades. $\mathrm{Al}$ respecto, cuando el recorrido transcurre junto al barrio de Benimaclet, se explica el origen y significado árabe de este nombre de lugar (Tabla 1). Este topónimo también sirve para explicar los procesos de urbanización de la huerta a raíz del crecimiento urbano de la ciudad. También en este punto se explican determinados usos urbanos y servicios públicos, al referirse al Cementeri de Benimaclet, creado a final del siglo XIX (1896-1899) debido a las epidemias de cólera y como medida higiénica para sustituir el cementerio anterior que se encontraba en el centro del barrio junto a la iglesia (antiguo pueblo de Benimaclet). Otro de los topónimos que hacen mención a asentamientos humanos es la Partida de Vera, del latín varius 'color grisáceo' (Tabla 1), tal vez por ser una zona endorreica y de marjal, donde la población vive diseminada en casas rurales (alquerías).

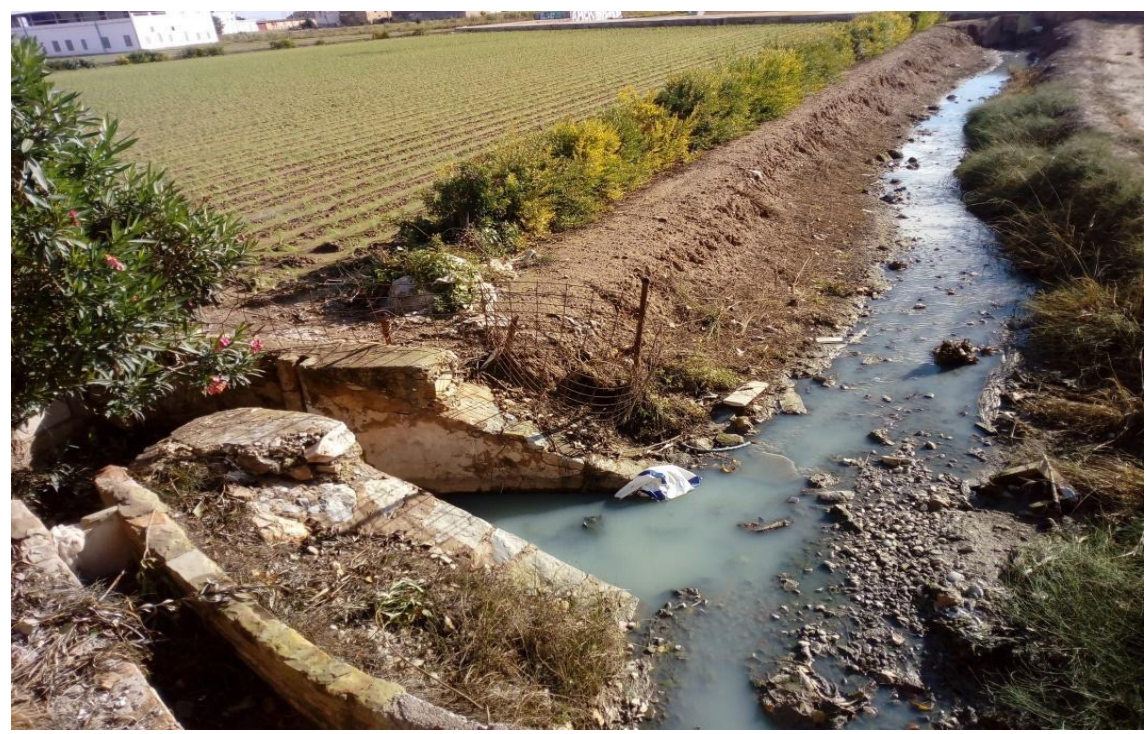

Figura 3. Aguas contaminadas en una de las acequias de la Partida de Vera (Benimaclet). Fotografía de los autores (2019). ${ }^{3}$

entiende como aquellas paradas que se realizan durante las salidas en la que se explican contenidos que tienen que ver con el significado del nombre del lugar (toponimia).

3 En la imagen se puede apreciar un partidor para distribuir las aguas de riego. El agua procede de la Acequia de Mestalla. 
TABLA 1

Topónimos que se explican durante la salida de campo 1

\begin{tabular}{|c|c|}
\hline \multicolumn{2}{|r|}{ València } \\
\hline Origen lingüístico & $\begin{array}{l}\text { Latín valens -entis 'que vale, que tiene valor, que es fuerte' (CASANOVA, } \\
\text { 2011: 285). }\end{array}$ \\
\hline Contenido semántico & $\begin{array}{l}\text { 1. Geografía Humana: asentamiento urbano. } \\
\text { 2. Geografía Humana: topónimo propagandístico (para atraer } \\
\text { colonos). }\end{array}$ \\
\hline Tipo de topónimo & $\begin{array}{l}\text { Nombre de una colonia romana fundada por colonos romanos en } 138 \\
\text { a.C. (según datos de Tito Livio en Ab Urbe Condita). }\end{array}$ \\
\hline Continuidad semántica & $\begin{array}{l}\text { Continúa siendo una urbe. Se trata de una de las grandes ciudades } \\
\text { más antiguas de Europa, ya que ha pervivido ininterrumpidamente } \\
\text { durante más de } 2 \text { milenios }\end{array}$ \\
\hline $\begin{array}{l}\text { Interés didáctico para la } \\
\text { enseñanza de las ciencias } \\
\text { sociales }\end{array}$ & $\begin{array}{l}\text { Ayuda a entender el proceso histórico de la configuración de esta } \\
\text { ciudad y el contexto de la Huerta de València ya desde época romana. } \\
\text { Se trataba de un espacio fértil y que desde hace } 2000 \text { años ha sido } \\
\text { transformado por la actividad humana y tras el paso de diferentes } \\
\text { civilizaciones. }\end{array}$ \\
\hline \multicolumn{2}{|r|}{ Séquia de Mestalla } \\
\hline Origen lingüístico & $\begin{array}{l}\text { Latín tardío mixta (femenino de mixtus) 'mezcla' + sufijo -alla } \\
\text { (Coromines, 1989-1997, v: 289). }\end{array}$ \\
\hline Contenido semántico & Geografía Humana: infraestructura de riego para la huerta. \\
\hline Tipo de topónimo & $\begin{array}{l}\text { Acequia para riego de la huerta. } \\
\text { Mezcla de aguas, porque describe un azud donde unas aguas siguen } \\
\text { por el río y otras se incorporan a la acequia de Mestalla. }\end{array}$ \\
\hline Continuidad semántica & $\begin{array}{l}\text { Desde su creación funciona como azud y acequia, aunque hoy es más } \\
\text { conocida por dar nombre a un barrio y al campo de fútbol del Valencia } \\
\text { C.F. }\end{array}$ \\
\hline $\begin{array}{l}\text { Interés didáctico para la } \\
\text { enseñanza de las ciencias } \\
\text { sociales }\end{array}$ & $\begin{array}{l}\text { Sirve para explicar el patrimonio hidráulico y las peculiaridades del } \\
\text { sistema de regadío de la Huerta de València. }\end{array}$ \\
\hline \multicolumn{2}{|r|}{ Séquia de Rascanya } \\
\hline Origen lingüístico & $\begin{array}{l}2 \text { opciones } \\
\text { 1. árabe rizq 'bien, propiedad, beneficio' }+ \text { Ain, 'fuente', el beneficio } \\
\text { que nos aporta la fuente (CoRomines, 1989-1997, vi: } 343 \text { ). } \\
\text { 2. latín resecare 'cortar, recortar' > tardolatino o mozárabe: riscare, } \\
\text { 'terreno recortado, riscoso, peña' (de donde proviene el castellano } \\
\text { risco). }\end{array}$ \\
\hline Contenido semántico & Geografía Humana: infraestructura de riego para la huerta. \\
\hline
\end{tabular}




\begin{tabular}{|c|c|}
\hline Tipo de topónimo & $\begin{array}{l}\text { Actual: acequia para riego de la huerta. } \\
\text { Anterior: } \\
\text { 1. Topónimo propagandístico referido a una acequia, que aporta } \\
\text { riqueza ya que riega los campos y produce alimentos. } \\
\text { 2. Se refiere a los riscos o peñas (en el término de Paterna) cercanos al } \\
\text { azud de Rascanya, de donde parte esta acequia. Aguas arriba de este } \\
\text { azud hay otro azud cuyo topónimo está definido por las mismas peñas } \\
\text { (azud de Tormos, "peñas"). }\end{array}$ \\
\hline Continuidad semántica & $\begin{array}{l}\text { Desde su creación funciona como azud y acequia, aunque hoy es } \\
\text { también conocida para dar nombre a un barrio y a un distrito de la } \\
\text { ciudad de València. }\end{array}$ \\
\hline $\begin{array}{l}\text { Interés didáctico para la } \\
\text { enseñanza de las ciencias } \\
\text { sociales }\end{array}$ & $\begin{array}{l}\text { Sirve para explicar el patrimonio hidráulico y las peculiaridades del } \\
\text { sistema de regadío de la Huerta de València. }\end{array}$ \\
\hline \multicolumn{2}{|r|}{ Fila Fonda } \\
\hline Origen lingüístico & $\begin{array}{l}\text { Catalán/valenciano fila 'canal secundario en el sistema de regadío de } \\
\text { la huerta de Valencia' (cf. reguero, hijuela) (AVL, 2016). }\end{array}$ \\
\hline Contenido semántico & Geografía humana: infraestructura de riego para la huerta. \\
\hline Tipo de topónimo & Acequia menor para riego de la huerta (Figura 3). \\
\hline Continuidad semántica & Desde su creación funciona como acequia de tercer nivel (hijuela). \\
\hline $\begin{array}{l}\text { Interés didáctico para la } \\
\text { enseñanza de las ciencias } \\
\text { sociales }\end{array}$ & $\begin{array}{l}\text { Sirve para explicar el patrimonio hidráulico y las peculiaridades del } \\
\text { sistema de regadío de la Huerta de València. }\end{array}$ \\
\hline \multicolumn{2}{|r|}{ Benimaclet } \\
\hline Origen lingüístico & $\begin{array}{l}\text { Árabe: ibn 'familia, hijos, clan' + mahlad 'linaje árabe' (BARCELó, 2010: } \\
\text { 96). }\end{array}$ \\
\hline Contenido semántico & Geografía humana: propiedad rústica (alquería). \\
\hline Tipo de topónimo & $\begin{array}{l}\text { Antigua alquería. Posteriormente convertida en pueblo (entre el siglo } \\
\text { xvı y 1878) y actualmente barrio de la ciudad de València. }\end{array}$ \\
\hline Continuidad semántica & $\begin{array}{l}\text { Continúa siendo uno de los barrios más conocidos y peculiares de } \\
\text { València y que aún mantiene cierta vida de pueblo. Este barrio tiene } \\
28.718 \text { habitantes (AYUNTAMIENTO DE VALĖNCIA, 2020). }\end{array}$ \\
\hline $\begin{array}{l}\text { Interés didáctico para la } \\
\text { enseñanza de las ciencias } \\
\text { sociales }\end{array}$ & $\begin{array}{l}\text { Sirve para explicar el asentamiento humano por parte de la cultura } \\
\text { islámica en la Huerta de València. También se utiliza para explicar los } \\
\text { procesos de urbanización de la huerta con el crecimiento urbanístico } \\
\text { de la ciudad de València. Se aprovecha la ocasión para explicar los } \\
\text { diferentes amenazadas de este espacio agrícola. }\end{array}$ \\
\hline \multicolumn{2}{|r|}{ Cementeri de Benimaclet } \\
\hline Origen lingüístico & 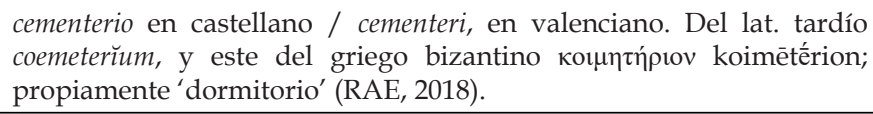 \\
\hline Contenido semántico & Geografía Humana: infraestructura para uso humano. \\
\hline Tipo de topónimo & Lugar para enterramiento de difuntos. \\
\hline
\end{tabular}




\begin{tabular}{|c|c|}
\hline Continuidad semántica & $\begin{array}{l}\text { Desde que se creó a finales del siglo xIx (1896-99) ha funcionado } \\
\text { como lugar de enterramiento de difuntos. Las terribles epidemias } \\
\text { de cólera de finales del siglo xIx provocaron su construcción, ya que } \\
\text { anteriormente el cementerio estaba dentro del pueblo de Benimaclet, } \\
\text { al lado de su iglesia. }\end{array}$ \\
\hline $\begin{array}{l}\text { Interés didáctico para la } \\
\text { enseñanza de las ciencias } \\
\text { sociales }\end{array}$ & $\begin{array}{l}\text { Sirve para explicar los usos urbanos y servicios públicos, así como } \\
\text { la causa de su construcción (epidemias de cólera de finales del siglo } \\
\text { xIX) y el crecimiento demográfico. Se aprovecha también para explicar } \\
\text { el proceso de urbanización ya que se encuentra actualmente en las } \\
\text { afueras del barrio de Benimaclet. }\end{array}$ \\
\hline \multicolumn{2}{|r|}{ Partida de Vera } \\
\hline Origen lingüístico & $\begin{array}{l}\text { Vera podría derivar del latín varius 'color grisáceo' (COROMINES, 1989- } \\
\text { 1997, vII: 459). }\end{array}$ \\
\hline Contenido semántico & Partida cuya tierra presenta un color grisáceo. \\
\hline Tipo de topónimo & $\begin{array}{l}\text { Tal vez se refiera a los pantanos que cubrían históricamente esta área, } \\
\text { antes de que fueran bonificados para cultivar la huerta. }\end{array}$ \\
\hline Continuidad semántica & $\begin{array}{l}\text { Sus áreas pantanosas (marjales) han desaparecido ya desde hace } \\
\text { siglos. Continúa siendo actualmente una partida agrícola, pero } \\
\text { amenazada por el crecimiento urbano de la ciudad de València y zona } \\
\text { costera (Playa la Patacona, en Alboraia) y vías de comunicación. }\end{array}$ \\
\hline $\begin{array}{l}\text { Interés didáctico para } \\
\text { enseñanza de las ciencias } \\
\text { sociales }\end{array}$ & $\begin{array}{l}\text { Esta área geográfica sirve de marco para explicar diferentes elementos } \\
\text { geográficos, desde la urbanización, agricultura, configuración } \\
\text { histórica de la Huerta de Valencia, hasta el riesgo de inundación. No } \\
\text { hay que olvidar que esta zona era un área pantanosa, de marjal. }\end{array}$ \\
\hline \multicolumn{2}{|r|}{ Séquia de Vera } \\
\hline Origen lingüístico & $\begin{array}{l}\text { Vera podría derivar del latín varius "color grisáceo" (COROMINES, 1989- } \\
\text { 1997, vII: 459). }\end{array}$ \\
\hline Contenido semántico & Geografía humana: infraestructura de riego para la huerta. \\
\hline Tipo de topónimo & $\begin{array}{l}\text { Se refiere a la acequia que nace de la acequia de Rascanya y que riega } \\
\text { la partida de Vera, cuya tierra presentaría un color grisáceo por sus } \\
\text { marjales. Esta acequia marca el límite entre los actuales términos de } \\
\text { València y Alboraia (antiguamente entre Benimaclet y Alboraia). }\end{array}$ \\
\hline Continuidad semántica & La acequia se creó como canal de riego y así continúa. \\
\hline $\begin{array}{l}\text { Interés didáctico para la } \\
\text { enseñanza de las ciencias } \\
\text { sociales }\end{array}$ & $\begin{array}{l}\text { Sirve para explicar el patrimonio hidráulico y las peculiaridades del } \\
\text { sistema de regadío de la Huerta de València. }\end{array}$ \\
\hline
\end{tabular}

Fuente: Elaboración propia.

Un segundo grupo de topónimos hace referencia al sistema de regadío tradicional de la Huerta de València. En esta parte de la salida de campo se explica el Tribunal de las Aguas, entidad que se encarga históricamente de dirimir los conflictos por el agua de riego entre los agricultores de 7 comunidades de regantes que componen las acequias del Turia (Quart-Benàger-Faitanar, Tormos, Mislata, Mestalla, Favara, Rascanya y Rovella). De estas 7 acequias, cabe indicar que 2 regaban o aun riegan campos de cultivo por donde discurren las 3 salidas de campo que aquí se exponen (acequias de Mestalla y Rascanya) (Tabla 1). A 
continuación, se explica el funcionamiento y jerarquía de las infraestructuras hidráulicas tradicionales: en primer lugar, se destacan los 7 azudes o presas del río Turia, desde donde derivan, respectivamente, cada una de las siete acequias principales citadas (séquia mare); posteriormente, el agua se ramifica a través de los llamados braços (brazos) y braçals (brazales); y, finalmente, en un tercer nivel se encuentran las llamadas files (filas, hijuelas) (Figura 4). De manera general, esta sería la jerarquización de la distribución de las aguas desde el río Turia. También, cabe indicar que el nombre de acequia puede hacer mención indistintamente a braços, braçals o files: es decir, se trata de un nombre general para mencionar a una infraestructura que deriva y transporta agua de riego. Además, cabe remarcar la complejidad de este sistema de riego, ya que hay acequias de entrada de agua a los campos de cultivo ('aguas vivas') y de salida, que recogen las aguas sobrantes ('aguas muertas') hacia el mar. Cabe indicar que antes de su evacuación al mediterráneo, estos mismos caudales pueden ser utilizados hasta en 6 o 7 bancales (Figura 5). Junto a la explicación del sistema de regadío de la Huerta de València se explica el origen y significado de este segundo grupo de topónimos (Tabla 1).

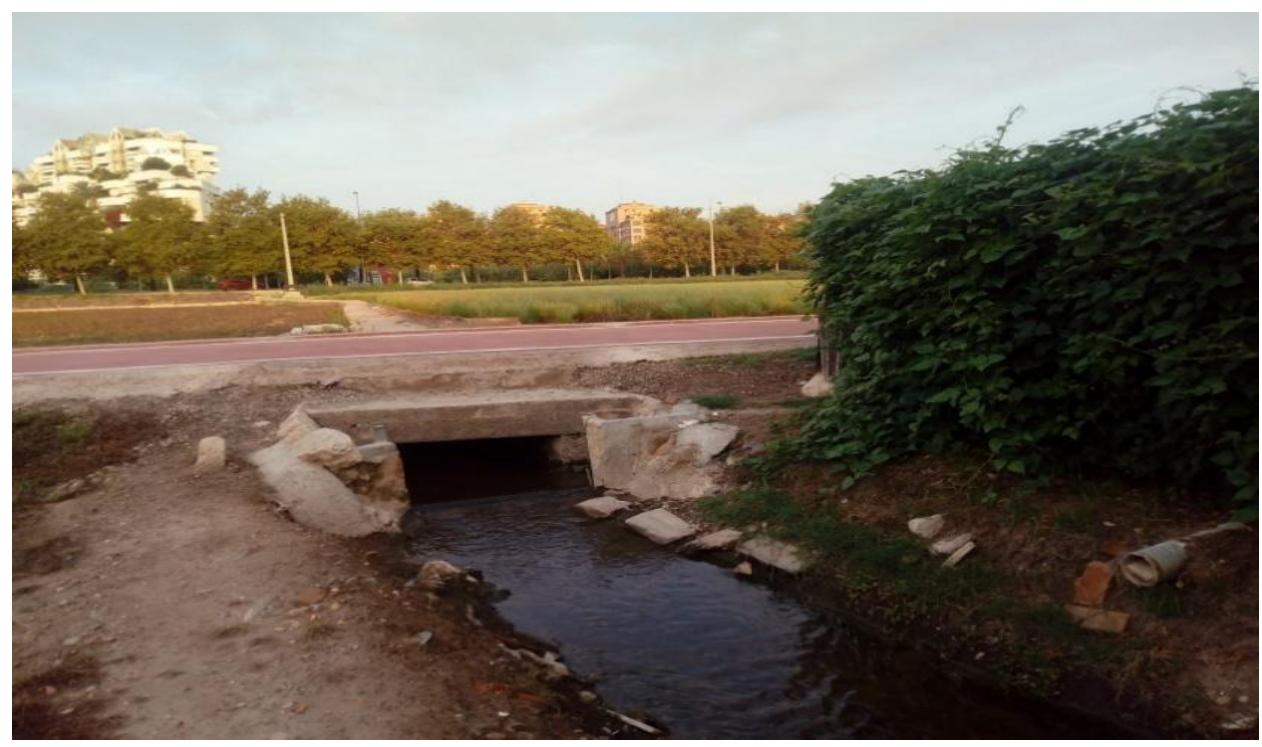

Figura 4. Fila Fonda (Partida de Vera). Fotografía de los autores (2018). ${ }^{4}$

4 En esta imagen se puede observar de fondo la parte nueva del barrio de Benimaclet, concretamente la Cooperativa de Edificios Espai Verd. El agua procede de la acequia de Mestalla. 


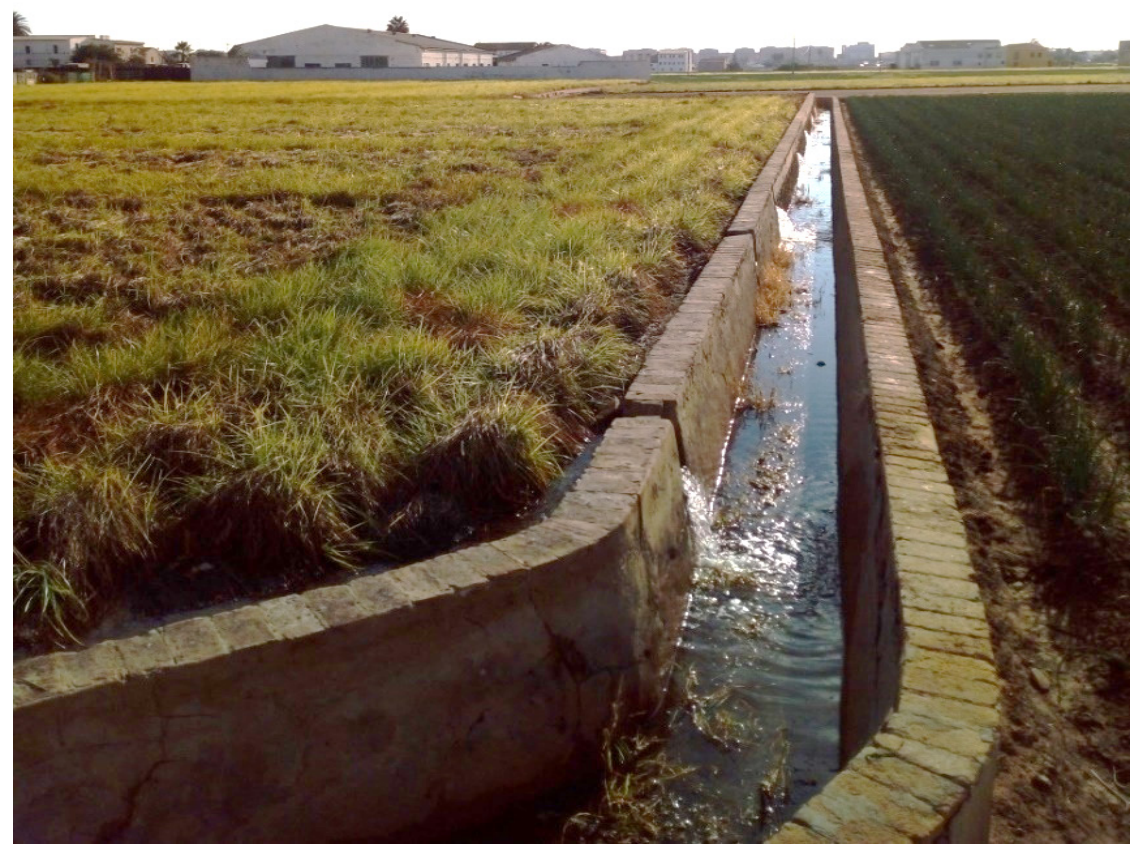

Figura 5. Riego de campos de cultivo de chufa (Alboraia). Fotografía de los autores (2018). ${ }^{5}$

\subsection{Salida de campo 2. Ocupación y adaptación del ser humano al medio}

La segunda salida de campo comienza en el mismo punto donde finaliza la primera (Figura 2). El tema general de este itinerario es mostrar cómo se ha producido la ocupación del territorio y la adaptación del ser humano a un territorio inundable. Esta temática (el riesgo de inundación) debe tratarse en la Educación Primaria como corrobora la normativa para el caso de las ciencias sociales en el Bloque 2, concretamente en el curso $3^{\circ}$ donde uno de los contenidos a tratar son las «Consecuencias de las sequías y las inundaciones para la vida de los seres humanos». En el comienzo de esta jornada se retoma la información de la salida de campo anterior y se vincula el área de estudio con su proceso de configuración y se introduce que antiguamente era una zona de marjal (se pregunta nuevamente por el topónimo de Vera). En cuanto al interés didáctico de la toponimia, los nombres que se explican son aquellos que tienen que ver con

5 En esta imagen se puede observar la salida de las aguas sobrantes ("aguas muertas"). El agua procede de la acequia de Rascanya. 
asentamientos humanos que han ocupado esta zona inundable (Partida de Vera). La idea es que el alumnado intente interpretar este territorio como una zona de riesgo, pero que el ser humano la ha bonificado y ocupado tradicionalmente. Por tanto, que entienda que se ha pasado de una relación de «riesgo-recurso» a «recurso-riesgo».

Por destacar algunos nombres, cabe citar el origen y definición del municipio de Alboraia, del árabe al-burayyaj 'la torrecilla' (BARCELó, 2010: 78) (Tabla 2). En su origen fue una torre de vigilancia musulmana que, tras la conquista cristiana, perdió su funcionalidad y a su alrededor se fueron agregando alquerías. Una de las construcciones típicas de la Huerta de València es la barraca, que pone de manifiesto la adaptación al medio por parte del ser humano con el uso de materiales y recursos disponibles en su entorno, como el barro y las cañas (se presta nuevamente atención a este espacio inundable). Por el recorrido de las 3 salidas de campo, tan solo en esta se pueden observar este tipo de construcciones, antaño muy habituales. Sin embargo, están desapareciendo por la pérdida de su funcionalidad (lugar de residencia tradicional o espacio para guardar apeos de labranza). En el dossier que se facilita al alumnado se indican varios nombres de estas viviendas y se hace especial atención a las Barracas del Bessó (Bessó es un linaje catalán/valenciano que significa 'gemelo') (Figura 6). Además de estos asentamientos también se explica la articulación del territorio a partir de caminos y sendas como el Camí del Farinós, del catalán/valenciano farinós ('harinero'). La finalidad de la explicación de este topónimo es vincular este espacio con la actividad agrícola ya que esta vía de comunicación era la que utilizaban los agricultores para transportar el trigo al Moli de Vera, edificio anexo a la Ermita de Vera. Finalmente, el recorrido de la segunda salida de campo concluye en la zona conocida como La Carrasca. Esta especie arbórea era un hito en el paisaje agrícola valenciano, ya que proporcionaba sombra (además de bellotas para el ganado). De la carrasca que hubo en el pasado y dio nombre al topónimo se desconoce su ubicación y debió desaparecer hace décadas posiblemente con la construcción de la Universitat Politècnica de València. 


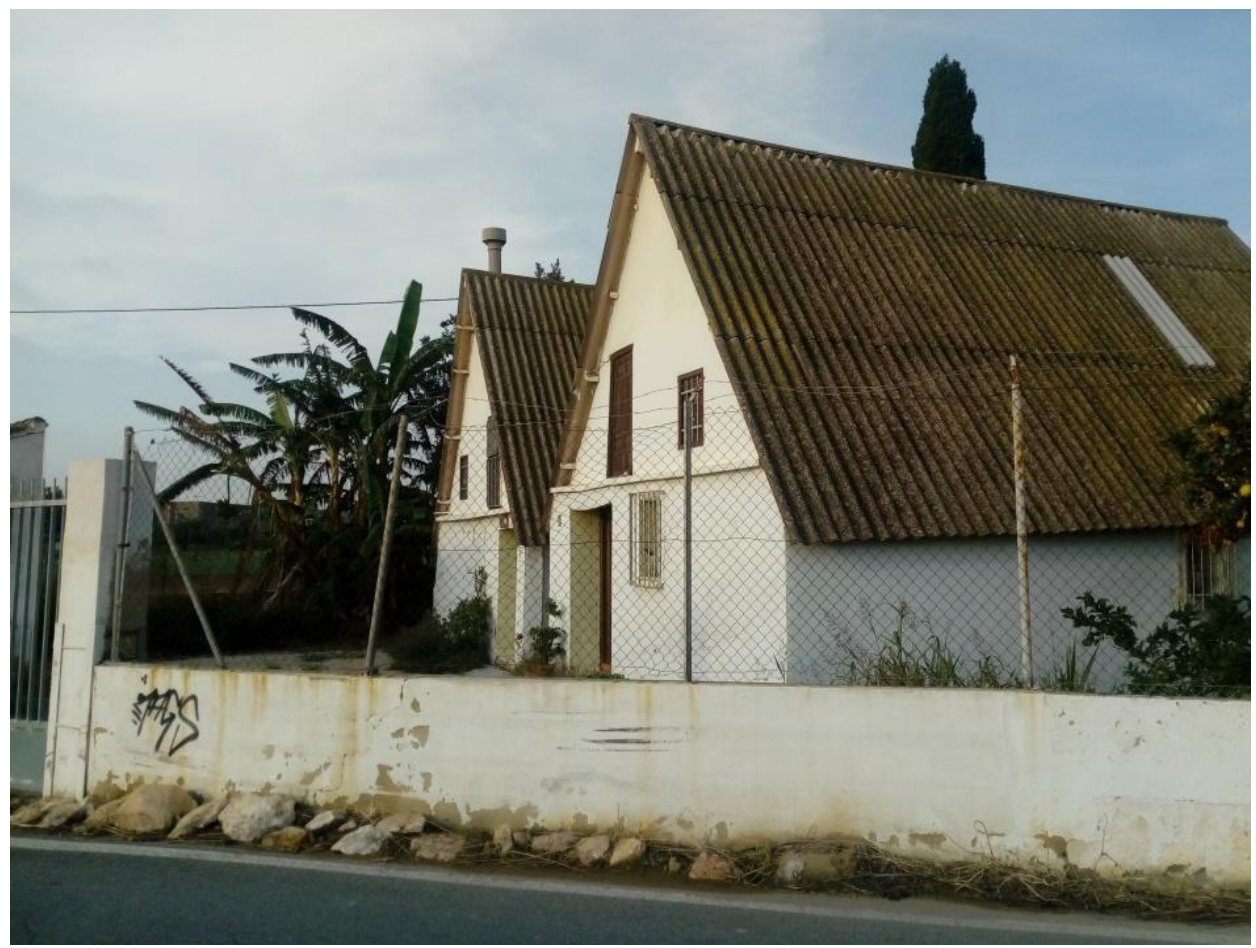

Figura 6. Barracas del Bessó (Camino del Farinós, Partida de Vera).

Fotografía de los autores (2019). ${ }^{6}$

TABLA 2

Topónimos que se explican durante la salida de campo 2

\begin{tabular}{|l|l|}
\hline \multicolumn{2}{|c|}{ Alqueria de Patac } \\
\hline Origen lingüístico & $\begin{array}{l}\text { Alqueria (val.) Alquería (cas.): árabe alqaríyya 'casa de labor con finca } \\
\text { agrícola'. } \\
\text { Patach: Valenciano patac, (patach suena 'patac', con la h muda) de la forma } \\
\text { valenciana pataca “patata". Es un apodo en referencia a una persona que } \\
\text { se dedicaba al cultivo de este tubérculo. }\end{array}$ \\
\hline Contenido semántico & Geografía Humana: propiedad rústica (alquería). \\
\hline Tipo de topónimo & $\begin{array}{l}\text { Hace referencia a una alquería (agrupación de casas) en el término } \\
\text { municipal de Alboraia. }\end{array}$ \\
\hline Continuidad semántica & $\begin{array}{l}\text { Desde su construcción en el siglo xvi, la alquería de Patac se usó con } \\
\text { fines agrícolas. Dada la escasa rentabilidad de las tareas agrícolas, en la } \\
\text { actualidad se ha reconvertido en lugar de celebración de todo tipo de } \\
\text { eventos. }\end{array}$ \\
\hline
\end{tabular}

6 Se puede observar como el tejado tradicional de cañas ha sido sustituido por otro de fibrocemento. Actualmente, la fachada de la barraca de la derecha se encuentra derrumbada. 


\begin{tabular}{|c|c|}
\hline $\begin{array}{l}\text { Potencialidad didáctica } \\
\text { para la enseñanza de } \\
\text { las ciencias sociales }\end{array}$ & $\begin{array}{l}\text { Su finalidad es vincular la actividad agrícola y los tipos de cultivo } \\
\text { característicos de la Huerta de València y ver cómo esto ha quedado } \\
\text { reflejado en la toponimia. Otros nombres vinculados con 'pataca' es el } \\
\text { de la playa de la Patacona (Alboraia). }\end{array}$ \\
\hline \multicolumn{2}{|r|}{ Alboraia } \\
\hline Origen lingüístico & Árabe: al-burayyaj 'la torrecilla' (BARCELÓ, 2010: 78). \\
\hline Contenido semántico & Geografía Humana: torre de vigilancia costera. \\
\hline Tipo de topónimo & Torre de vigilancia costera para defenderse de ataques cristianos. \\
\hline Continuidad semántica & $\begin{array}{l}\text { Tras la Reconquista, dejó de ser una torre y pasó a ser una partida. Luego } \\
\text { se convirtió en una alquería, y finalmente en pueblo. Actualmente es un } \\
\text { municipio con } 24.454 \text { habitantes (INE, 2020). }\end{array}$ \\
\hline $\begin{array}{l}\text { Interés didáctico para } \\
\text { la enseñanza de las } \\
\text { ciencias sociales }\end{array}$ & $\begin{array}{l}\text { Sirve para explicar el proceso de configuración histórica de la Huerta } \\
\text { de València (pasado musulmán). También se aprovecha este topónimo } \\
\text { para explicar uno de los cultivos genuinos de esta parte de la Huerta de } \\
\text { València (la chufa, para la elaboración de horchata). }\end{array}$ \\
\hline \multicolumn{2}{|r|}{ Camí del Farinós } \\
\hline Origen lingüístico & Catalán/valenciano: farinós ('harinero'). \\
\hline Contenido semántico & Geografía humana: infraestructura para uso humano. \\
\hline Tipo de topónimo & $\begin{array}{l}\text { Es un molino que sirve para moler del grano del cereal y convertirlo en } \\
\text { harina. }\end{array}$ \\
\hline Continuidad semántica & $\begin{array}{l}\text { Todavía existe este molino, pero ha dejado de funcionar como tal (Molí } \\
\text { de Vera) debido a las inundaciones de la Riuá de 1957. En la actualidad } \\
\text { es un museo etnográfico perteneciente a la Universidad Politécnica de } \\
\text { Valencia. }\end{array}$ \\
\hline $\begin{array}{l}\text { Interés didáctico para } \\
\text { la enseñanza de las } \\
\text { ciencias sociales }\end{array}$ & $\begin{array}{l}\text { La finalidad de la explicación de este topónimo es vincular este espacio } \\
\text { con la actividad agrícola ya que esta vía de comunicación era la que } \\
\text { utilizaban los agricultores para transportar el trigo al molino de Vera. }\end{array}$ \\
\hline \multicolumn{2}{|r|}{ Barraques del Bessó } \\
\hline Origen lingüístico & $\begin{array}{l}\text { Catalán/valenciano: Bessó 'linaje catalán o valenciano que significa } \\
\text { gemelo'. }\end{array}$ \\
\hline Contenido semántico & Geografía Humana: antropónimo. \\
\hline Tipo de topónimo & $\begin{array}{l}\text { Se refiere a unas barracas (vivienda construida con barro y cañas) que } \\
\text { eran propiedad de una familia que se apellidaba Bessó. }\end{array}$ \\
\hline Continuidad semántica & $\begin{array}{l}\text { Actualmente son de las pocas barracas que quedan en uso en la Partida } \\
\text { de Vera (Figura 5). }\end{array}$ \\
\hline $\begin{array}{l}\text { Interés didáctico para } \\
\text { la enseñanza de las } \\
\text { ciencias sociales }\end{array}$ & $\begin{array}{l}\text { Sirve para explicar el patrimonio etnológico y la vinculación y } \\
\text { adaptación de este territorio por la sociedad. Principalmente se explica } \\
\text { la función de estas construcciones y los materiales de construcción } \\
\text { (cañas y barro) que, son materiales que se pueden encontrar en esta área. } \\
\text { No cabe olvidar que esta es una zona de marjal, donde las cañas es una } \\
\text { de la vegetación natural característica. }\end{array}$ \\
\hline \multicolumn{2}{|r|}{ Ermita de Vera } \\
\hline Origen lingüístico & $\begin{array}{l}\text { Vera podría derivar del latín varius 'color grisáceo' (CoROMINES, 1989- } \\
\text { 1997, vII: 459). }\end{array}$ \\
\hline Contenido semántico & Geografía Humana: infraestructura para uso humano. \\
\hline
\end{tabular}


La toponimia como recurso didáctico para la enseñanza de la Geografía

\begin{tabular}{|c|c|}
\hline Tipo de topónimo & $\begin{array}{l}\text { La Partida de Vera poseía un poblamiento diseminado notable y su } \\
\text { centro de culto era esta ermita y que venera a la Inmaculada Concepción. }\end{array}$ \\
\hline Continuidad semántica & $\begin{array}{l}\text { El origen de la ermita se remonta al siglo } \mathrm{xV} \text {, aunque el actual templo es } \\
\text { del siglo xviII. Sigue funcionando como ermita. }\end{array}$ \\
\hline $\begin{array}{l}\text { Interés didáctico para } \\
\text { la enseñanza de las } \\
\text { ciencias sociales }\end{array}$ & $\begin{array}{l}\text { Sirve para explicar la ocupación humana de este espacio, la Partida de } \\
\text { Vera, un espacio rural donde residían los agricultores en diseminado y } \\
\text { donde este edificio de culto religioso articulaba esta partida. }\end{array}$ \\
\hline \multicolumn{2}{|r|}{ La Carrasca } \\
\hline Origen lingüístico & $\begin{array}{l}\text { Catalán/valenciano carrasca ('encina') (Quercus ilex ssp. rotundifolia) } \\
\text { (castellano carrasca). Etimología prelatina. }\end{array}$ \\
\hline Contenido semántico & Geografía Física: árbol. \\
\hline Tipo de topónimo & $\begin{array}{l}\text { La carrasca era un hito en el paisaje agrícola, ya que proporcionaba } \\
\text { sombra (además de bellotas para el ganado). De la carrasca que hubo } \\
\text { en el pasado y dio nombre al topónimo se desconoce su ubicación, } \\
\text { debió desaparecer hace décadas posiblemente con la construcción de la } \\
\text { Universitat Politècnica de València. }\end{array}$ \\
\hline Continuidad semántica & $\begin{array}{l}\text { En la actualidad la carrasca ha sobrevivido como un topónimo que } \\
\text { nombra a un barrio de la ciudad de València. Este barrio incluye los dos } \\
\text { mayores campus universitarios de la ciudad, Universitat Politècnica de } \\
\text { València y Campus de Tarongers (Universitat de València) y una popular } \\
\text { parada de tranvía (muy concurrida por alumnado universitario). }\end{array}$ \\
\hline $\begin{array}{l}\text { Interés didáctico para } \\
\text { la enseñanza de las } \\
\text { ciencias sociales }\end{array}$ & $\begin{array}{l}\text { Sirve para explicar este tipo de vegetación mediterránea. En el área } \\
\text { litoral solía asociarse a antiguas casas de campo. }\end{array}$ \\
\hline \multicolumn{2}{|r|}{ Senda de la Carrasca } \\
\hline Origen lingüístico & $\begin{array}{l}\text { Catalán/valenciano carrasca ('encina') (Quercus ilex ssp. rotundifolia) } \\
\text { (castellano carrasca). Etimología prelatina. }\end{array}$ \\
\hline Contenido semántico & Geografía Humana: odónimo. \\
\hline Tipo de topónimo & $\begin{array}{l}\text { Se refiere a una senda que comenzaba en la actual avenida del Primat } \\
\text { Reig (norte de la ciudad de València) y que seguía hacia el mar a través de } \\
\text { la huerta donde actualmente se localizan los dos campus universitarios. }\end{array}$ \\
\hline Continuidad semántica & $\begin{array}{l}\text { Dejó de funcionar como senda. Hoy su trama (enterrada bajo el asfalto) } \\
\text { es irreconocible. }\end{array}$ \\
\hline $\begin{array}{l}\text { Interés didáctico para } \\
\text { la enseñanza de las } \\
\text { ciencias sociales }\end{array}$ & $\begin{array}{l}\text { Se vincula con el topónimo de la Carrasca y sirve para explicar las } \\
\text { antiguas vías de comunicación de esta parte de la Huerta de València, } \\
\text { hoy desaparecidas por la ocupación urbana. }\end{array}$ \\
\hline
\end{tabular}

Fuente: Elaboración propia.

\subsection{Salida de campo 3. La destrucción de la Huerta de Valencia. Urbanización y antiguos espacios agrícolas relictos}

La última salida de campo tiene el objetivo de enseñar a los discentes el proceso de urbanización del antiguo espacio de la Huerta de València en el área que ocupa la antigua partida de Algirós (hoy barrio) e inmediaciones de los barrios 
de El Cabanyal y El Canyamelar. Durante el recorrido se presta especial atención a determinadas construcciones e infraestructuras que se han ido edificando desde 1960 hasta la actualidad. También, se visitan algunos lugares y patrimonio típico de la huerta que aún se puede observar y que refleja la economía tradicional de este espacio singular. Respecto a la toponimia, los nombres que se describen durante este tercer itinerario son los que tienen que ver con el sistema de regadío, los asentamientos humanos y las vías de comunicación (Tabla 3). En cuanto a los primeros, cabe destacar el nombre de Algirós, del árabe (al-jarux, canalización). Se trata, por tanto, de una antigua área donde el sistema de regadío (articulado por la acequia de Mestalla) era de tal importancia que dio lugar a este topónimo (Tabla 3). Algunas de las ramificaciones de la acequia de Mestalla y que en la actualidad se encuentran soterradas son el Braçal de l'Arquet (del catalán/valenciano arquet, 'arquillo') (AVL, 2016), el Braç d'Escamarda (relacionado con un antropónimo), y el Braç de Rams (de Rams, apellido propio de Catalunya y València), cuyo trazado se sitúa bajo el Campus de Tarongers (Universitat de València) y conduce el agua que riega algunas huertas residuales de este espacio.

TABLA 3

Topónimos que se explican durante la salida de campo 3.

\begin{tabular}{|l|l|}
\hline \multicolumn{2}{|c|}{ Algirós } \\
\hline Origen lingüístico & Árabe: al-jarux 'canalización'. \\
\hline Contenido semántico & Geografía Humana: infraestructura de riego para la huerta. \\
\hline Tipo de topónimo & Se refiere a una canalización o acequia para el riego de época islámica. \\
\hline Continuidad semántica & $\begin{array}{l}\text { En la actualidad existe todavía la acequia de Algirós, pero este topónimo } \\
\text { es más conocido por designar un distrito de València que recibe su } \\
\text { nombre. Este barrio tiene censados 36.711 habitantes (AYunTAMIENTo DE } \\
\text { VALĖNCIA, 2020). }\end{array}$ \\
\hline $\begin{array}{l}\text { Potencialidad didáctica } \\
\text { para la enseñanza de } \\
\text { las ciencias sociales }\end{array}$ & $\begin{array}{l}\text { Este topónimo se utiliza para explicar la vinculación de esta parte de la } \\
\text { ciudad de València con el sistema de regadío tradicional. Se trata de una } \\
\text { antigua partida rural que ha sido urbanizada desde los años setenta. }\end{array}$ \\
\hline \multicolumn{2}{|c|}{ Braçal de l'Arquet } \\
\hline Origen lingüístico & $\begin{array}{l}\text { Catalán/valenciano: braçal ('ramal de acequia') (AVL, 2016). } \\
\text { Catalán/valenciano: arquet ('arquillo') (AVL, 2016). }\end{array}$ \\
\hline Contenido semántico & Geografía Humana: infraestructura de riego para la huerta. \\
\hline Tipo de topónimo & $\begin{array}{l}\text { Braçal se refiere a un ramal que deriva del Braç (ramal principal de } \\
\text { acequia) de Rambla, y este, a su vez, del Braç de Rams y este último, de } \\
\text { la acequia de Mestalla. } \\
\text { Arquet se refiere a un pequeño arco que describía la acequia seguramente } \\
\text { para superar algún desnivel natural o artificial. }\end{array}$ \\
\hline
\end{tabular}




\begin{tabular}{|c|c|}
\hline Continuidad semántica & $\begin{array}{l}\text { Hoy su uso para riego es residual (ha perdido su funcionalidad) y su } \\
\text { trazado está enterrado bajo el Campus de Tarongers de la Universitat de } \\
\text { València. }\end{array}$ \\
\hline $\begin{array}{l}\text { Potencialidad didáctica } \\
\text { para la enseñanza de } \\
\text { las ciencias sociales }\end{array}$ & $\begin{array}{l}\text { Sirve para explicar el pasado agrícola y el sistema de regadío de esta } \\
\text { parte de la ciudad de València. }\end{array}$ \\
\hline \multicolumn{2}{|r|}{ Braç d'Escamarda } \\
\hline Origen lingüístico & Árabe: probable antropónimo. \\
\hline Contenido semántico & Geografía Humana: antropónimo. \\
\hline Tipo de topónimo & $\begin{array}{l}\text { Actualmente se refiere a un braç (ramal de acequia) que, a su vez, deriva } \\
\text { del Braç de Rams, y este de la acequia de Mestalla. }\end{array}$ \\
\hline Continuidad semántica & $\begin{array}{l}\text { En la actualidad su trazado está enterrado bajo el campus universitario } \\
\text { de Vera (Universitat Politècnica de València). Continúa más allá de esta y } \\
\text { riega algunas huertas cercanas a la línea de costa (Playa de la Patacona, } \\
\text { Alboraia). }\end{array}$ \\
\hline $\begin{array}{l}\text { Potencialidad didáctica } \\
\text { para la enseñanza de } \\
\text { las ciencias sociales }\end{array}$ & $\begin{array}{l}\text { Sirve para explicar el pasado agrícola y el sistema de regadío de esta } \\
\text { parte de la ciudad de València. }\end{array}$ \\
\hline \multicolumn{2}{|r|}{ Braç de Rams } \\
\hline Origen lingüístico & $\begin{array}{l}\text { Catalán/valenciano: braç (ramal de acequia) y Rams (apellido propio de } \\
\text { Catalunya y València). }\end{array}$ \\
\hline Contenido semántico & Geografía humana: antropónimo. \\
\hline Tipo de topónimo & $\begin{array}{l}\text { Actualmente se refiere a un braç (ramal de acequia) que, a su vez, deriva } \\
\text { de la Acequia de Mestalla. }\end{array}$ \\
\hline Continuidad semántica & $\begin{array}{l}\text { En la actualidad su trazado está enterrado bajo el Campus de Tarongers } \\
\text { de la Universitat de València. Continúa más allá y riega algunas huertas } \\
\text { residuales del entorno de este campus (Figura 6). }\end{array}$ \\
\hline $\begin{array}{l}\text { Potencialidad didáctica } \\
\text { para la enseñanza de } \\
\text { las ciencias sociales }\end{array}$ & $\begin{array}{l}\text { Sirve para explicar el pasado agrícola y el sistema de regadío de esta } \\
\text { parte de la ciudad de València. }\end{array}$ \\
\hline \multicolumn{2}{|r|}{ El Cabanyal } \\
\hline Origen lingüístico & $\begin{array}{l}\text { Catalán/valenciano: cabanya 'construcción rústica' (castellano cabaña) } \\
+ \text { sufijo colectivo - al. }\end{array}$ \\
\hline Contenido semántico & Geografía Humana: infraestructura para vivienda. \\
\hline Tipo de topónimo & $\begin{array}{l}\text { Su origen se remonta al siglo XIII, cuando un grupo de pescadores } \\
\text { comenzaron la edificación en primera línea de playa (a } 4 \mathrm{~km} \text { del centro } \\
\text { de la ciudad de València) de cabañas, que acabaron dando nombre al } \\
\text { actual barrio del Cabanyal, citado por primera vez en } 1422 \text { (SANCHIS, 2009: } \\
\text { 16). A su alrededor se desarrolló un núcleo urbano que actualmente } \\
\text { forma el barrio del Cabanyal (antiguo municipio de Poble Nou de la Mar). }\end{array}$ \\
\hline Continuidad semántica & $\begin{array}{l}\text { En la actualidad no quedan restos de las cabañas originales. El nombre } \\
\text { de Cabanyal está asociado a uno de los barrios con mayor personalidad } \\
\text { de la ciudad de València. }\end{array}$ \\
\hline
\end{tabular}




\begin{tabular}{|c|c|}
\hline $\begin{array}{l}\text { Potencialidad didáctica } \\
\text { para la enseñanza de } \\
\text { las ciencias sociales }\end{array}$ & $\begin{array}{l}\text { Sirve para explicar la vinculación entre la sociedad rural-pesquera con } \\
\text { el territorio. Se trata de un barrio que se adaptó a las condiciones físico- } \\
\text { ecológicas (en paralelo a la línea de costa) y viviendas de construcción } \\
\text { muy primarias (principalmente barro y cañas) que eran los recursos } \\
\text { disponibles y accesibles para su construcción. }\end{array}$ \\
\hline \multicolumn{2}{|r|}{ El Canyamelar } \\
\hline Origen lingüístico & $\begin{array}{l}\text { Catalán/valenciano: canyamel ('Planta perenne') (Saccharum officinarum), } \\
\text { de la que se extrae el azúcar"' (castellano cañamiel o caña de azúcar) + } \\
\text { sufijo colectivo -ar. }\end{array}$ \\
\hline Contenido semántico & Geografía Humana: cultivo. \\
\hline Tipo de topónimo & $\begin{array}{l}\text { Se sabe que hacia el siglo xv (antes de la pequeña edad de hielo) el Reino } \\
\text { de València producía azúcar para Barcelona, como lo testifican varios } \\
\text { documentos, entre los cuales, uno de } 1415 \text { se refiere a algunas posesiones } \\
\text { de cañamiel en las huertas de València y de Castelló (SALICRU, 1995: 189). } \\
\text { Quizá, algunas de estas posesiones dieron nombre a Canyamelar. }\end{array}$ \\
\hline Continuidad semántica & $\begin{array}{l}\text { Han desaparecido los cultivos de caña de azúcar y hoy el Canyamelar } \\
\text { configura un barrio anexo al Cabanyal. De hecho, el nombre del actual } \\
\text { barrio es Cabanyal-Canyamelar. }\end{array}$ \\
\hline $\begin{array}{l}\text { Potencialidad didáctica } \\
\text { para la enseñanza de } \\
\text { las ciencias sociales }\end{array}$ & $\begin{array}{l}\text { Sirve para explicar la vinculación del ser humano con el medio, en este } \\
\text { caso la actividad rural. }\end{array}$ \\
\hline \multicolumn{2}{|r|}{ Camí Vell del Cabanyal } \\
\hline Origen lingüístico & Catalán/valenciano: camí vell ('camino viejo'). \\
\hline Contenido semántico & Geografía humana: odónimo. \\
\hline Tipo de topónimo & $\begin{array}{l}\text { Se refiere a un camino que discurría desde el centro de la ciudad de } \\
\text { València hasta el barrio del Cabañal. }\end{array}$ \\
\hline $\begin{array}{l}\text { La continuidad } \\
\text { semántica }\end{array}$ & $\begin{array}{l}\text { Sobre la parte occidental de este camino se superpuso la avenida Blasco } \\
\text { Ibánez y solo sobrevive en su parte oriental, yuxtapuesto en parte al } \\
\text { Campus de Tarongers de la Universitat de València en las cercanías del } \\
\text { cementerio del Cabanyal (Figura 6). }\end{array}$ \\
\hline $\begin{array}{l}\text { Potencialidad didáctica } \\
\text { para la enseñanza de } \\
\text { las ciencias sociales }\end{array}$ & $\begin{array}{l}\text { Sirve para explicar cómo el proceso urbano de la ciudad de València } \\
\text { prácticamente ha hecho desaparecer las antiguas vías de comunicación } \\
\text { que enlazaban con la ciudad y los antiguos poblados marítimos. Este } \\
\text { topónimo se relaciona con el del barrio y el cementerio del Cabanyal. }\end{array}$ \\
\hline \multicolumn{2}{|r|}{ Cementeri del Cabanyal } \\
\hline Origen lingüístico & 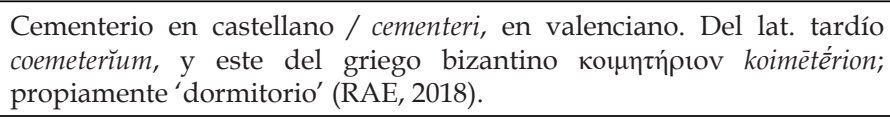 \\
\hline Contenido semántico & Geografía Humana: infraestructura para uso humano. \\
\hline Tipo de topónimo & Lugar para enterramiento de difuntos. \\
\hline Continuidad semántica & $\begin{array}{l}\text { Hasta } 1867 \text { los entierros se realizaban junto a la Parroquia del pueblo } \\
\text { (Cabanyal), pero luego se construyó un cementerio a las afueras, junto al } \\
\text { Camino Viejo del Cabanyal. }\end{array}$ \\
\hline
\end{tabular}




\begin{tabular}{|l|l|}
\hline $\begin{array}{l}\text { Potencialidad didáctica } \\
\text { para la enseñanza de } \\
\text { las ciencias sociales }\end{array}$ & $\begin{array}{l}\text { Al igual que el Cementerio de Benimaclet, sirve para explicar los usos } \\
\text { urbanos y servicios públicos, así como la causa de su construcción } \\
\text { (epidemias de cólera definales del sigloxix) y el crecimiento demográfico. } \\
\text { Se aprovecha también para explicar el proceso de urbanización ya que } \\
\text { se encuentra actualmente insertado en la trama urbana de la ciudad de } \\
\text { València. }\end{array}$ \\
\hline
\end{tabular}

Fuente: Elaboración propia.

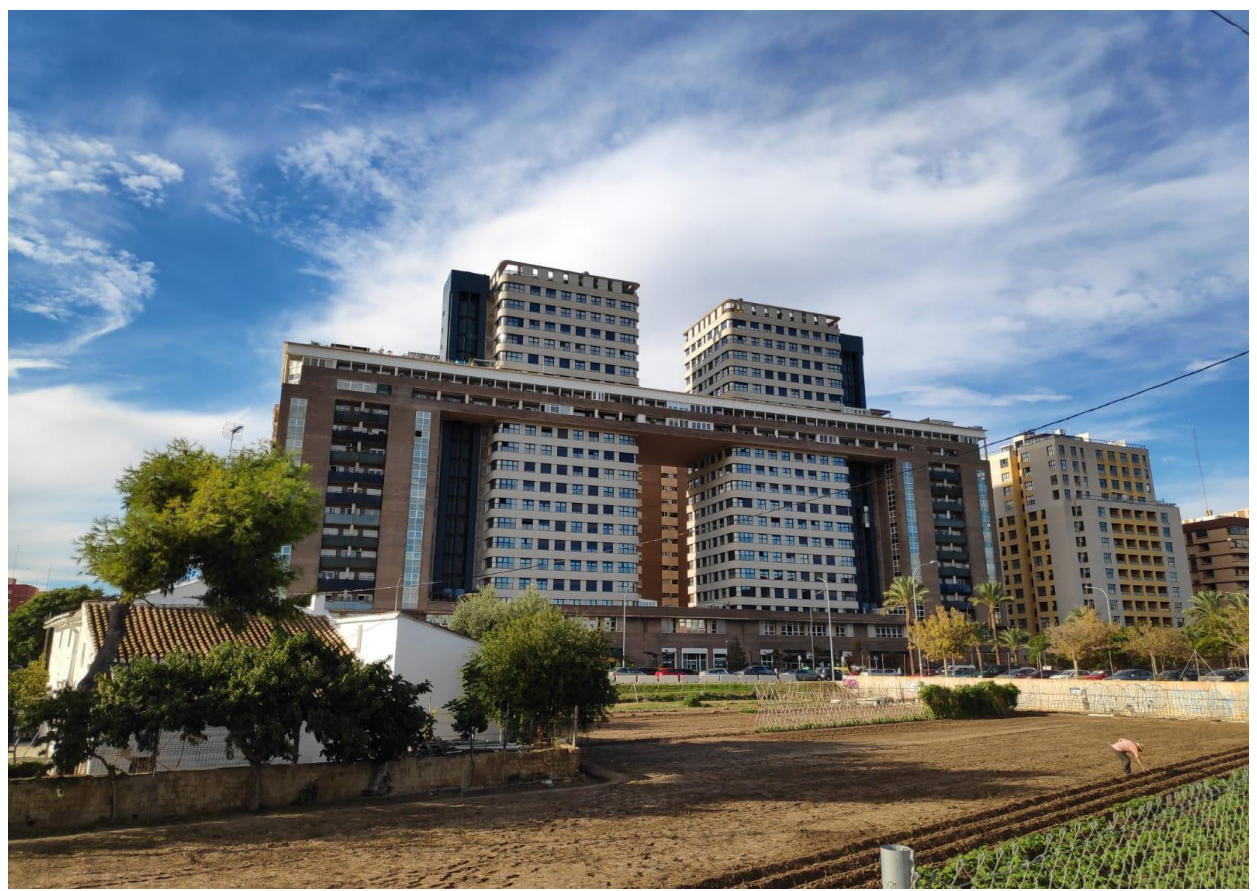

Figura 7. Panorámica y contraste entre el espacio urbanizado y antiguas huertas (Camí Vell del Cabanyal, Algirós). Fotografía de los autores (2018). ${ }^{7}$

En vinculación con segundo grupo de topónimos (asentamientos humanos y vías de comunicación) se explica El Cabanyal (del catalán/valenciano cabanya 'construcción rústica' -castellano cabaña) + sufijo colectivo -al). Su origen se remonta al siglo xIII, cuando un grupo de pescadores comenzó la edificación de cabañas en primera línea de costa (a $4 \mathrm{~km}$ del centro de la ciudad de Valencia), que acabaron dando nombre al actual barrio de El Cabanyal, citado por primera

7 Nota: en la imagen se observa a uno de los pocos agricultores que aún mantienen estas huertas residuales. 
vez en 1422 (SANCHIS, 2009). A su alrededor se desarrolló un núcleo urbano que actualmente forma el barrio del Cabanyal (antiguo municipio de Poble Nou de la Mar). Un segundo topónimo que se describe es El Canyamelar (del catalán/valenciano canyamel 'planta perenne (Saccharum officinarum), de la que se extrae el azúcar' (castellano cañamiel o caña de azúcar) + sufijo coletivo -ar). De este nombre se sabe que hacia el siglo xv (antes de la pequeña edad de hielo) el Reino de València producía azúcar para Barcelona, como lo testifican varios documentos, entre los cuales, uno de 1415 se refiere a algunas posesiones de cañamiel en las huertas de València y de Castelló (SALICRú, 1995). Quizá, alguna de estas posesiones dio nombre a El Canyamelar. Finalmente, durante el itinerario se discurre por el casi desaparecido Camí Vell del Cabanyal, que comunica con el cementeri del Cabanyal. Cabe indicar que este punto se caracteriza por la presencia de alguna huerta relicta y casa de labor, solares y edificios de viviendas de las décadas 1980 y 1990, y da una imagen de contraste, fruto del intenso proceso urbanizador que sigue amenazando la Huerta de València (Figura 7).

\section{DISCUSIONES}

Con este trabajo se ha expuesto una propuesta de cómo enseñar e interpretar el territorio con el uso de la toponimia. El marco geográfico seleccionado (la Huerta de València), sin duda, es un espacio de interés por los cambios acaecidos durante las últimas décadas, así como la toponimia vinculada con el patrimonio agrícola, hidráulico, cultural, social y/o ambiental. Como se ha recogido en las tablas, todos los topónimos identificados y que se explican durante las salidas de campo tienen un interés didáctico que permite explicar determinados procesos que afectan a la Huerta de València. Esta utilidad de los nombres de lugar, también ha sido explicada como sostienen ORDINAS y BINIMELIS (2018) ya que tradicionalmente, la toponimia constituye una herramienta pedagógica de gran valor, a pesar de haber sido ignorada y criticada por ser obsoleta y fundamentada en el abuso del ejercicio memorístico. Al respecto, Ordinas (2014) indica que con la toponimia no solo se aprende geografía y otras ciencias sociales, sino que también en diferentes aspectos de la vida cotidiana permiten obtener una formación integral, al experimentar la interdisciplinariedad tanto en el manejo de contenidos como de técnicas auxiliares. Por su parte, FrIERA (1992) indica que los nombres de lugar ofrecen en el proceso de enseñanza-aprendizaje una enorme utilidad en el conocimiento del medio, tanto en la adquisición de conceptos y terminología, como en procedimientos y valores en la didáctica de las ciencias sociales.

En cuanto a la interpretación del territorio a partir de los nombres de lugar, ORDINAS (2014) se refiere a las ventajas del uso de la toponimia a la hora de interpretar el espacio geográfico, que consisten en: 1) familiarización con el territorio y las fuentes cartográficas y documentales; y 2) descubrimiento de la historia y la geografía regionales y mejora del conocimiento del medio. Respecto a este último, ORDINAS y BINIMELIs (2018) explican que el análisis de los nombres de 
lugar no solo desvela las claves para la interpretación del paisaje (actual y pasado), sino que también facilita la observación directa del territorio, donde el trabajo de campo (con la ayuda de fuentes cartográficas, orales y documentales) resulta imprescindible. Respecto a lo anterior, Мовоте (2014) afirma que la toponimia es el ADN de un territorio, de ahí su utilidad a la hora de explicar geografía.

ORDINAS (2014) hace hincapié en el proceso de la recuperación de la toponimia como recurso didáctico para la enseñanza de esta ciencia. Este autor explica que Canadá y Estados Unidos recuperaron en su enseñanza el interés por su tesoro toponímico. Por ejemplo, la Comisión de Toponimia de Canadá ofrece todo tipo de recursos para el mundo de la enseñanza relacionados con este recurso, al igual que el británico Ordnance Survey que, a través de la toponimia vehicula informaciones culturales y geográficas con enlaces dirigidos a la búsqueda y visualización cartográfica. Para el caso de Australia, la Comisión de Nombres Geográficos, ofrece posibilidades con todo tipo de recursos vinculados con la toponimia del país, al igual que la difusión de documentales donde se hace hincapié al valor patrimonial y la necesidad de preservar las formas autóctonas de sus nombres de lugar (PAReLla, 2008).

En España, el trabajo de Gómez et al. (2015), para el caso de la Educación Primaria, tiene el objetivo de demostrar el potencial didáctico de la toponimia para enseñar la diversidad de un área de estudio y hacer emerger territorios vulnerables o sometidos a riesgos. Estos autores argumentan que los nombres de lugar ofrecen un valor singular como recurso complementario para el análisis territorial y son susceptibles de uso como herramienta didáctica en los procesos de enseñanza-aprendizaje de las ciencias sociales. Por su parte, ORDINAS y BiNIMELIS (2018) se centran en sistematizar las diversas áreas temáticas del medio natural que se pueden tratar desde el estudio de la toponimia que caracteriza un determinado territorio. También en España, un estudio reciente elaborado por Domínguez et al. (2020) pone de manifiesto que la toponimia destaca por su eficacia para la educación en igualdad, pese a las dificultades manifestadas por el alumnado, como el escaso número de calles con nombre de mujeres o la dificultad para acceder a sus biografías. Estas autoras han llegado a la conclusión de que se observa en positivo que el alumnado sienta interés por realizar actividades con perspectiva de género, así como los aprendizajes conseguidos. Otras notables referencias dentro de la literatura española son las de Riesco (2010) y las de Membrado e Iranzo $(2017 ; 2018)$, que tratan sobre los topónimos como fuente de conocimiento y de valoración del territorio. Por su lado, el trabajo de LUISA DE TORT (2014) pone el énfasis en como el paisaje, a través de sus topónimos, se convierte en una herramienta pedagógica fundamental para el estudio y el conocimiento geográfico.

En el ámbito latinoamericano, en Argentina, la investigación de Gilio (2015) tiene la finalidad de introducir, desde una visión antropológica, el uso de la cartografía y los nombres de lugar como herramientas didácticas en la interpretación del territorio, concebido como una construcción socio-histórica. Para ello, utiliza como recurso didáctico la cartografía antigua y moderna, así como diversos nombres para un mismo territorio. En México, Valenzuela (2010) 
ha puesto de manifiesto que la riqueza lingüística, tomando en consideración la cantidad de las lenguas nativas americanas, de la población que las habla y de los topónimos existentes, es motivo para su conservación, estudio y divulgación. Este autor ha estudiado algunos nombres de lugar en lengua náhuatl para corroborar su vinculación con aspectos de la geografía física o humana. En relación con la geografía como ciencia y disciplina escolar, este autor indica que puede contribuir de diferentes formas, no solo para contabilizar y ubicar a los grupos indígenas, sino a través del estudio de la forma en que el espacio geográfico influye en las características socio-culturales y económicas. Por ejemplo, VAlenzuela (2010) muestra como la influencia del espacio geográfico, sin que se perciba de forma aparente, está presente en el significado del nombre de muchos lugares.

En el ámbito anglosajón destacan diferentes referencias sobre pedagogía y toponimia como las de Alderman y Reuben (2020), donde desarrollan un marco pedagógico para transformar las aulas en espacios toponímicos donde el estudiantado pueda intervenir en la política de renombrar sus propias instituciones educativas. Por su parte, HeIKKILA (2008) lleva a cabo un método de enseñanza a través de la toponimia para recuperar antiguos nombres indígenas en un territorio de la Columbia Británica y educar a la vez sobre dicho territorio y sobre su lengua e historia oral. En el caso del estudio de ALDERMAN (2016), este autor interpreta las connotaciones de los topónimos que designan paisajes culturales y su papel como armas de poder político.

\section{CONCLUSIONES}

Como conclusión, con la presentación de esta propuesta del uso de la toponimia a partir de salidas de campo en la Huerta de València, se ha puesto de manifiesto el potencial didáctico de los nombres de lugar para explicar geografía, especialmente en la vertiente que relaciona el ser humano con el medio a lo largo de la historia (Ciencias Sociales). Por tanto, la toponimia, aunque suele obviarse para explicar este tipo de relación, debería tener un mayor protagonismo, tanto en el campo teórico como en las salidas de campo. La propuesta que aquí se expone va más allá del caso de estudio presentado, ya que puede servir de paradigma para enseñar ciencias sociales utilizando un recurso patrimonial y vinculándolo a cualquier territorio. Respecto a la formación del profesorado (no sólo de Educación Primaria, sino en todas las etapas), la toponimia es un recurso que debe estar presente durante su labor docente a la hora de describir cualquier territorio, sea en el aula o fuera de ella.

En cuanto a los retos de investigación, se pretenderá en el fututo analizar si el profesorado en formación incorpora la toponimia como recurso didáctico en las salidas de campo que deben plantear en la asignatura (práctica que se les pide tras la realización de los 3 itinerarios). Para finalizar, cabe añadir que el análisis de los nombres de lugar permite obtener unos resultados que confirman el predominio histórico de unos nombres de lugar que describen un paisaje agrícola fosilizado en 
sus topónimos, pero transformado en la realidad. Este análisis permite descubrir la enorme riqueza patrimonial que oculta la toponimia, y no solo es útil para la enseñanza de la geografía, sino que, además, desde una perspectiva identitaria, permite a las personas que residen o frecuentan el área de estudio redescubrir, aunque solo sea virtualmente, un paisaje cultural hoy desaparecido.

\section{REFERENCIAS}

Academia Valenciana de la Lengua (AVL) (2016): Diccionari normatiu valencià, Publicacions de l'Acadèmia Valenciana de la Llengua, València.

Alderman, D. (2016): «Place, naming and the interpretation of cultural landscapes», en B. Graham y P. Howard (eds.), Heritage and Identity, Routledge, London: 195-213.

Alderman, D.H.; Reuben, R.R. (2020): «The classroom as "toponymic workspace": towards a critical pedagogy of campus place renaming», Journal of Geography in Higher Education, 44 (1): 124-141.

Arroyo, F. (2018): «La toponimia como patrimonio cultural inmaterial», Boletín de la Real Sociedad Geográfica, 153: 33-60.

Ayuntamiento de ValènCia (2020): Estadística. Demografía [En línea].

BALLANTYNE, R. (1996): «Factors affecting student choice of geography as a senior secondary school subject in Queensland», International Research in Geographical and Environmental Education, 5 (3): 172-185.

BARCELó, C. (2010): Noms aràbics de lloc. IIFV-Bromera, València.

Casanova, E. (2011): «Comunidad Valenciana». A: Toponimia hispánica. Origen y evolución de nuestros topónimos más importantes», Denes, València: 257292.

Conedera, M., Vassere, S., NefF, C., Meurer, M. y Krebs, P. (2007): «Using toponymy to reconstruct past land use: a case study of 'brüsáda'(burn) in southern Switzerland», Journal of Historical Geography, 33 (4): 729-748. doi: 10.1016/j. jhg.2006.11.002

COMES, P. y DANTí, J. (2003): «Rastres. Una eina pedagógica per al coneixement de la historia local i comarcal», Ponències. Revista del Centre d'Estudis de Granollers, 11-25.

Coromines, J. (1989-1997): Onomasticon Cataloniae. Els noms de lloc i noms de persona de totes les terres de llengua catalana, VIII vol. Curial Edicions Catalanes, Barcelona.

CRespo, J.M. (2012): «Un itinerario didáctico para la interpretación de los elementos físicos de los paisajes de la Sierra de Guadarrama», Didáctica Geográfica, 13: 15-34.

CRespo, J. M. (2019): «El visualizador Iberpix 4 del Instituto Geográfico Nacional: un recurso didáctico para la interpretación de los componentes físicos del paisaje», Enseñanza de las ciencias de la tierra: Revista de la Asociación Española para la Enseñanza de las Ciencias de la Tierra, 27 (2): 182-191. 
DARBY, H.C. (1957): «Place names and geography», The Geographical Journal, 123: 387-392.

De LÁZARo, M.L.; Crespo, J.M.; GómeZ, M.L. (2014): «Los paisajes agrarios de España en la Nube», en R. Martínez-Medina (coord.), Nuevas perspectivas conceptuales y metodológicas para la educación geográfica, 2: 319-334.

Delgado, B.; Torres, F.J.; García, A.; OJedA, J.F. (2013): «El viaje como aprendizaje significativo y pertinente. Crónica de una experiencia andaluza», en P. PANEQUe y J.F. OJEDA (eds.), El viaje en la geografía moderna, Universidad Internacional de Andalucía, Sevilla: 429-444.

Domínguez, A.; Ortuño, B.; DíEZ, R. (2020): «Mujeres en los callejeros. Una estrategia para incluir la perspectiva de género en las asignaturas de Didáctica de las Ciencias Sociales», en R. RoIg (coord.), La docencia en la Enseñanza Superior: Nuevas aportaciones desde la investigación e innovación, Universidad de Alicante, Alicante: 952-961.

Dorion, H. (1984): Les relations entre la toponymie et les autres sciences sociales. 450 ans de noms de lieux française en amerique du nord, Les publications du Québec, Québec.

Estepa, J.; CuenCA, J.M.; MartíN, M.J. (2011): «Enseñar y aprender las Sociedades Actuales e Históricas a través del Patrimonio en la Educación Primaria», en R. López, L. Velasco, V.M. Santidrián y X.A. Armas (coords.), Pensar históricamente en tiempos de globalización: actas del I Congreso Internacional sobre enseñanza de la historia, Universidade de Santiago de Compostela, Santiago de Compostela: 243-254.

FERNÁNDEZ, J. (2017): «La salida de campo como recurso didáctico para conocer el espacio geográfico: El caso de la ciudad de Valladolid y de Soria», Didáctica Geográfica, 18: 91-109.

FERNÁNDEZ, R.; Gómez, A.; LuENGO, M.Á. (2019): «Aprendiendo a interpretar el territorio: estudio de la fitotoponimia en la provincia de Salamanca», Boletín de la Asociación de Geógrafos Españoles, 82: 1-33. doi: http:/ /dx.doi.org/10.21138/ bage. 2816

FraGo, J.A. (1991): «Problemas, métodos y enseñanzas de la toponimia», en A. Líbano y H. ZumalacárRegui (coord.), Actas de las I Jornadas de onomástica, toponimia, Vitoria-Gasteiz, abril de 1986 = I Onomastika jardunaldien agiriak toponimia, Gasteiz: 199-220.

FrIERA, F. (1992): «Utilidad de la toponimia para el conocimiento del entorno», Lletres asturianes: Boletín Oficial de l'Academia de la Llingua Asturiana, 45: 35-44.

García de Celis, A.; Martínez, L.C.; Prieto, I. (2018): «Patrimonio cultural inmaterial en las Reservas de la Biosfera cantábricas: la recuperación de la toponimia en los Valles de Omaña y Luna (León)», Estudios geográficos, 79: 191-208.

GILIO, B. (2015): «El uso de la cartografía y la toponimia como recursos didácticos en la enseñanza secundaria de geografía: análisis de una experiencia áulica», Informe Científico Técnico UNPA, 7 (1): 121-143.

Gómez-Ruíz, M.L. (2010): «El tratamiento de la información a partir de fuentes cartográficas como procedimiento esencial de la enseñanza-aprendizaje de la Geografía en el bachillerato», en M.J. MARRóN, (coord.), Geografía, educación y 
formación del profesorado en el marco del espacio europeo de educación superior, Vol. 1, AGE, Madrid: 329-344.

Gómez, A.; Sevilla, J.; Fernández, R. (2015): «Hacer emerger la diversidad de espacios y los lugares vulnerables a través de un recurso de escasa visibilidad en el currículo de la educación primaria: la toponimia», en A.M. HERNÁNDEZ, C.R. García y J.L. De la Montaña (coord.), Una enseñanza de las ciencias sociales para el futuro: Recursos para trabajar la invisibilidad de personas, lugares y temáticas, Universidad de Extremadura, Cáceres: 183-192.

Gómez, A., Corrochano, D. y PARRA, G. (2017): «Itinerarios didáctico-naturales en Educación Primaria: el noroeste de Zamora», Didáctica Geográfica, 18: 111-131. HeIKKILA, K. (2008): Teaching through toponymy: using indigenous place-names in outdoor science camps. VDM Publishing.

Institut CARTogràfic VAlencià (ICV) (2020): Visor cartográfico. 2020 [En linea].

Instituto Nacional de Estadística (INE) (2020): Padrón municipal. 2020 [En linea].

IRANZO, E. (2014): «La Huerta de Valencia. Incertidumbre para un paisaje cultural ancestral», en F. Molinero, F. (coord.), Atlas de los paisajes agrarios de España, Ministerio de Agricultura, Alimentación y Medio Ambiente, Madrid: 512532.

López-Fernández, J.A. y PerAL, A.J. (2017): «Las Vías Verdes: escenario para trabajar el medio rural en Educación Primaria», Didáctica Geográfica», 18: 171192.

LUISA DE TORT, J. (2014): «El paisaje como pedagogía del territorio», Didáctica geográfica, 6: 133-153.

MARRón, M.J. (2011): «Enseñar y aprender Geografía a partir de distintos lenguajes: una experiencia de trabajo por proyectos para estudiar el clima de España a partir de los refranes», Anales de geografía de la Universidad Complutense, 31 (1): 107-123.

MArrón, M.J. (2013). «Tratamiento interdisciplinar de la Geografía, la Historia y el Arte con estudiantes del Grado de Magisterio. Una propuesta de enseñanza activa a través de un itinerario didáctico», en R. De Miguel y M.L. De LÁzARo, Innovación en la enseñanza de la geografía ante los desafios sociales y territoriales, Institución Fernando el Católico, Zaragoza: 331-352.

Mas, A. (1999): «Introducció a la Toponímia. Anàlisi i proposta didàctica», Revista del Vinalopó, 2 :7-25.

Membrado, J. C. (2014): «L'expansió urbana a costa de l'horta», en La Universitat de València i els seus entorns naturals: L'Horta de València, el Massís del Caroig, el Carrascal de la Font Roja i la Serra de Mariola, Universitat de València, Valencia: 20-23.

Membrado, J. C. (2017): «La relación entre toponimia urbana y topografía en la Ciutat Vella de Valencia: análisis mediante métodos cuantitativos y cualitativos», Boletín de la Asociación de Geógrafos Españoles, 74: 361-386. doi: https://doi.org/10.21138/bage.2458

Membrado, J. C. (2018): «El papel de la geografía en el análisis del contenido semántico de los topónimos. El caso de Alicante», Anales de geografía de la Universidad Complutense, 38 (1): 35-60. doi: https://doi.org/10.5209/ 
AGUC.60468.

Membrado, J. C. e Iranzo, E. (2017). «Los nombres de lugar como elementos evocadores del paisaje histórico. Análisis de la toponimia de los núcleos de población de la cuenca del Vinalopó», Investigaciones Geográficas, 68: 191-207.

Membrado, J. C. e Iranzo, E. (2018). «Anàlisi toponímica de l’Horta de València. Integració dels enfocaments clàssic i crític per a la reconstitució i revaloració del seu paisatge», Documents d'Anàlisi Geogràfica, 64(2): 247-269.

Morote, A.F. (2014): La toponimia de San Vicente del Raspeig a partir de los Bosquejos Planimétricos de 1898. Ayuntamiento de San Vicente del Raspeig, Concejalía de Cultura, San Vicente del Raspeig.

Morote, A.F. (2019): «Las salidas de campo en España como recurso didáctico para la enseñanza de la Geografía. Una revisión bibliográfica», Geographicalia, 71: 27-49.

Morote, A.F. (2020): «Recuerdos y experiencias de la Geografía Escolar. Caso de estudio de la asignatura de Geografía de las Regiones del Mundo (Universidad de Alicante)», en R. Roig-ViLA (ed.), La docencia en la Enseñanza Superior. Nuevas aportaciones desde la investigación e innovación educativas, Octaedro, Barcelona: 333-342.

Ordinas, A. (2014): «El potencial didáctico de la toponimia en la enseñanza de la Geografía», en R. Martínez-Medina y E.M. Tonda-Monllor (coords.), Nuevas perspectivas conceptuales y metodológicas para la educación geográfica, Vol. 2: 521532.

OrdinAS, A.; Binimelis, J. (2018): «Los nombres de lugar: un recurso didáctico en la enseñanza geográfica del paisaje natural», Anales de Geografía de la Universidad Complutense, 38(2): 385-408. doi: http:/ / dx.doi.org/10.5209/AGUC.62485.

Parella, M. (2008): «Informació toponímica: tendències actuals i futures en un context internacional», Revista Catalana de Geografia, Jornada de treball: Toponímia cartogràfica. Tendències actuals i futures: XII, 34.

Parra, D.; Morote, A.F. (2020): «Memoria escolar y conocimientos didácticodisciplinares en la representación de la educación geográfica e histórica del profesorado en formación», Revista Interuniversitaria de Formación del Profesorado, 95 (34.3): 11-32. doi: https:/ / doi.org/10.47553/rifop.v34i3.82028.

Real Academia Española (RAE) (2018): Diccionario de la lengua Española [En linea].

RiEsCO, P. (2010): «Nombres en el paisaje: la toponimia, fuente de conocimiento y aprecio del territorio», Cuadernos Geográficos, 46: 7-34.

SALICRÚ, R. (1995): El tràfic de mercaderies a Barcelona segons els comptes de la lleuda de Mediona (febrer de 1434), I. Barcelona: CSIC (Milà i Fontanals).

SANCHIS, A. (2009): Historia del Cabanyal. Poble Nou de la Mar (1238-1897). L'Oronella, València.

Sebastián, M. y De Miguel, R. (2017): «Educación geográfica 2020: Iberpix y Collector for ArcGis como recursos didácticos para el aprendizaje del espacio», Didáctica Geográfica, 18: 231-246.

SEIDL, N.P. (2018): «Engraved in the Landscape: The Study of Spatial and Temporal Characteristics of Field Names in the Changing Landscape», Names, Vol. 67 (1): 1-14. Doi.: 10.1080/00277738.2017.1415539. 
SiWEI, Q.; MEngJun, K.; Min, W. (2016): «Toponym mapping: a case for distribution of ethnic groups and landscape features in Guangdong, China», Journal of Maps, 12: 546-550. doi: 10.1080/17445647.2016.1201017.

SORIANO, V. (2015): La huerta de Valencia: Un paisaje menguante. CreateSpace, Charleston.

TORRES, M. (1995): «Toponímia i escola: una proposta didàctica», Eivissa, 26: 20-23.

VALENZUELA, E. (2010): «¿Es posible aprender Geografía a través de la toponimia?», Investigación Universitaria Multidisciplinaria: Revista de Investigación de la Universidad Simón Bolívar 9: 16-26.

West, R.C. (1954): "The Term "Bayou" in the United States: A Study in the Geography of Place Names», Annals of the Association of American Geographers, 44 (1): 63-74. 